\title{
Use of Standards and Ergonomics Principles Evaluation in Iran Furniture Industry (A Case Study: Manufacturing Units of Tehran Province)
}

\author{
Anooshe Fazeli $^{1}$ iD, Hassan Ghasembeygi², Mohammad Ghofrani ${ }^{*}$ iD
}

1. PhD Student, Department of Wood Technology and Engineering, Faculty of Wood and Paper Engineering, Gorgan University of Agricultural Sciences and Natural Resources, Gorgan, Iran

2. MSc Graduated Student, Department of Wood and Paper Sciences and Technology, Faculty of Materials Engineering and New Technologies, Shahid Rajaee Teacher Training University, Tehran, Iran

3. Professor, Department of Wood and Paper Sciences and Technology, Faculty of Materials Engineering and New Technologies, Shahid Rajaee Teacher Training University, Tehran, Iran

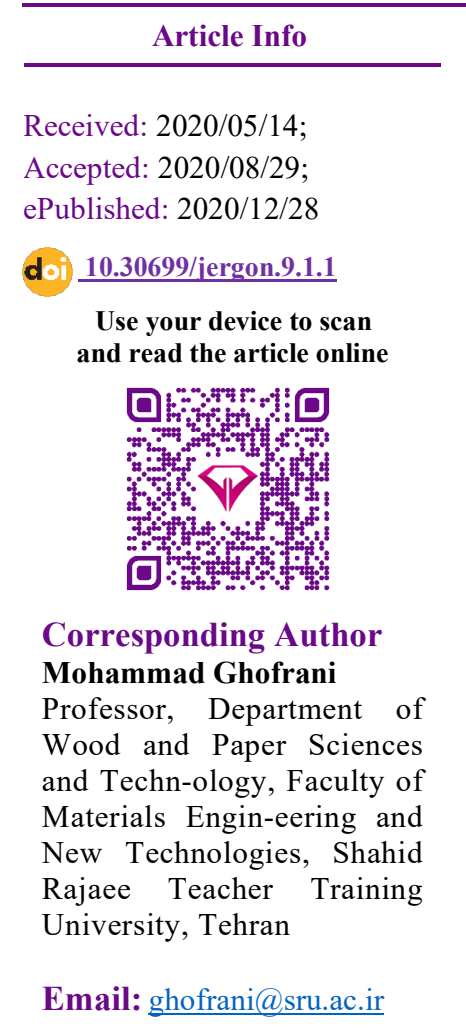

\begin{abstract}
Background and Objectives: During the past times people have used furniture as today. Along with the social welfare development and the importance of manufacturing efficiency, the importance of ergonomics and standardization in furniture became very clear so that, today it is well-known that not considering human factors in furniture manufacturing causes much human health problems. Due to the importance of furniture standardization, the present study was conducted to investigate the use of standards in furniture manufacturing units in Tehran province.
\end{abstract}

Methods: In this study, cluster sampling was performed and questionnaires were distributed among experienced manufacturers of sixty furniture manufacturing units. Statistical analysis was performed using One sample student t-test and Friedman test in SPSS 18 software.

Results: Results revealed that there was a significant difference between the indices mean and the hypothesized mean of the population. Furniture manufacturers believed that the governmental and nongovernmental institutions have appeared weak on updating furniture standards and making manufacturers familiar with standards. From their point of view, consumers have shown a great trend to buy standard and ergonomic furniture. Manufacturers also have largely tended so much to use standards and national standards conformed byinternational standards.

Conclusion: The manufacturing of standard furniture increases the consumer interest to buy furniture and it increases the consumer satisfaction. The high quality of imported raw materials makes furniture competitive and itcauses coordination with international standards and it can assure the successful export of furniture in Iran. Successful furniture manufacturing will depend on realization of all indices mentioned in the present study.

Keywords: Standard, Furniture industry, Ergonomics, Furniture manufacturers

Copyright (C) 2021, This is an original open-access article distributed under the terms of the Creative Commons Attribution-noncommercial 4.0 International License which permits copy and redistribute of the material just in noncommercial usages with proper citation.

How to Cite This Article:

Fazeli A, Ghasembeygi H, Ghofrani M. Use of Standards and Ergonomics Principles Evaluation in Iran Furniture Industry (A Case Study: Manufacturing Units of Tehran Province). Iran J Ergon. 2021; 9 (1) :102-117 


\section{Extended Abstract}

\section{Introduction}

During the past times people have used furniture as today. Along with the social welfare development and the importance of manufacturing efficiency, the importance of ergonomics and standardization in furniture became very clear so that, today it is well-known that not considering human factors in furniture manufacturing causes much human health problems. Due to the importance of furniture standardization, the present study was conducted to investigate the use of standards in furniture manufacturing units in Tehran province.

\section{Methods}

In this study, cluster sampling was performed and questionnaires were distributed among experienced manufacturers of sixtyfurniture manufacturing units. Statistical analysis was performed using One sample student t-test and Friedman test in SPSS 18 software (SPSS Inc., Chicago, Ill., USA).

\section{Results}

Results revealed that there was a significant difference between the indices mean and the hypothesized mean of the population. Furniture manufacturers believed that the governmental and nongovernmental institutions have appeared weak on updating furniture standards and making manufacturers familiar with standards. From their point of view, consumers have shown a great trend to buy standard and ergonomic furniture. Manufacturers also have largely tended so much to use standards and national standards conformed by international standards.

\section{Discussion}

Implementation and Updating of Standards by Governmental and Non-Governmental Institutions

Advertising is the most powerful tool for identifying companies, goods, services and ideas and creates a mentality in the audience and makes them interested in a subject to some extent [21]. Familiarization of furniture manufacturers with the standards is achieved through advertising and information, holding training workshops and conferences related to the introduction and application of standards. Existence of strong organizations and specialized unions in the field of furniture can play an important role in the development and growth of the country's furniture industry by playing various roles such as education and promotion, research and development, standardization, lobbying with the government and social responsibilities [4]. The government is obliged to encourage consumers to use domestic products by creating a culture, and the lack of strong trade unions in support of producers and the government's lack of support for domestically produced furniture are two important factors in the abandonment of the furniture industry in the country. In addition, furniture manufacturers are weak in terms of scientific foundations, knowledge of new production technologies and management principles, and unions and trade unions do not play their role in holding training and information courses properly. Also, in the program of specialized organizations and unions, much attention should be paid to the context, culture and promotion of knowledge and experience of other nations [2, $22,23]$. In order to develop the country's furniture industry, they should pay more attention to furniture manufacturers, and this will be possible by monitoring, promoting and informing the manufacturers about the standards by these institutions, and it is also necessary to update and adapt the standards to the needs of the furniture industry.

\section{Consumer Desire to Buy Standard and Ergo- nomic Furniture}

In modern marketing, customer orientation and attention to customer (consumer) satisfaction is one of the things that ensure the survival of companies. Improving customer satisfaction will lead to profitability and increase companies' share in the competitive market [24]. Therefore, one of the issues that furniture manufacturers must always address is meeting the needs of consumers [19]. Paying attention to human or ergonomic factors means observing the physical issues related to human-object 
relations (such as the back angle of the sofa with its floor, the height of the sofa, the sitting angle, the back angle of the sofa and the armrest, etc.). Failure to observe these can lead to physical harm to consumers [25]. Suitable furniture is the one that imposes the least pressure and tension on the body [2]. In furniture design, anthropometry and ergonomics usually go hand in hand [26].In the present study, analyzing the results of the index of consumer willingness to buy standard and ergonomic furniture, it was found that consumer satisfaction with ergonomic furniture is desirable and also compared to other factors in the purchase of furniture, ergonomic furniture. In addition, consumers to some extent demand furniture according to their anthropometric dimensions. By examining the results, it can be seen that the production of furniture by observing the standards and principles of ergonomic design, will increase consumers' desire to buy and increase their satisfaction.

\section{Manufacturers' Desire for Ergonomic Standar- ds and Principles}

One of the main bottlenecks in the furniture industry is the lack of skilled and specialized labor and lack of applied training, and this has reduced the quality of products and services, limited the use of advanced technology in production and increased costs [19]. In furniture production, the existence of skilled labor is very important and skilled and experienced manpower is considered as the basis and axis of sustainable development [29]. Failure to use data related to anthropometric dimensions in product design is a waste of various resources including human resources, finance and time [30]. The research of Ghofrani and Mohamad Moradi showed that technical and human factors are among the indicators affecting the competitiveness of classical furniture [27]. Although the manufacturers were not professionally familiar with the standards; According to the first indicator of this research, this could be due to the weak role of governmental and nongovernmental institutions, but their product was not outside the principles of standard and ergonomics. On the other hand, the analysis of the results showed that the sub-indicators of using the standards, the criterion for purchasing it and the willingness of manufacturers to participate technically, were at a desirable level.

\section{Compliance of National Standards with Intern- ational Ones}

From the formation of global markets until today, product quality has always been one of the main factors to stabilize and maintain market position [16]. According to Stafford et al., one of the most profitable strategies for most manufacturing industries is to produce high quality products, and the quality of manufactured products is critical to survival and profitability [32]. Gudarzi and Mohamad Moradi stated that one of the factors influencing economical production and successful export in the country's furniture industry is the guarantee of quality raw materials [27]. According to the research of Alizadeh et al., high quality raw materials are among the effective indicators on the development of wooden furniture exports in Iran [31]. Tajdini et al.also expressed that the timely and appropriate supply of raw materials required in the wooden furniture industry and the possibility of using various and new raw materials while maintaining appropriate quality parameters, will continue quality production in the final product unit and ultimately becomes a competitive price compared to similar foreign goods [17]. Standardization of product components and updating of the product to the standards defined at the international level are among the most important principles that companies active in the field of export must provide [3]. In the present study, according to the results of the analysis of the index of compliance with national and international standards, imported raw materials should comply more with the standards so that using the high quality of imported raw materials and standards will lead to competitiveness of the furniture being harmonized with international furniture standards which will be a guarantee for the successful export of wooden furniture in the country.

\section{Ranking of Indicators}

Evaluation criteria for using the standards were ranked by Friedman test. Based on the results, with $95 \%$ confidence, there was a difference between the 
mean rankings. The first rank was related to consumers' desire to buy standard and ergonomic furniture; in other words, from the perspective of furniture manufacturers, the most importance was given to the index of consumers' desire for standard furniture. Indicators of manufacturers' willingness to comply with standards in furniture manufacturing and compliance with national and international standards were ranked next; however, regarding the role of governmental and non-governmental institutions in the familiarity of manufacturers with standards and also updating the standards of the furniture industry, it was given the lowest rank by manufacturers and therefore needs more attention in this area. Ghofrani and Ghiyasvand study examining the views of furniture manufacturers on the production and sale of furniture showed that the indicators of customer orientation, cooperation with academics, imported furniture, design and satisfaction with government and guild support are of the highest to least importance [19]. Since customer orientation means paying attention to consumers and gaining their satisfaction [34], the findings of the present study were consistent with the results of Ghofrani and Ghiyasvand [19].

\section{Conclusion}

The manufacturing of standard furniture increases the consumer interest to buy furniture and it increases the consumer satisfaction. The high quality of imported raw materials makes furniture competitive and itcauses coordination with international standards and it can assure the successful export of furniture in Iran. Successful furniture manufacturing will depend on realization of all indices mentioned in the present study.

\section{Acknowledgement}

The authors thank all the loved ones who helped them in this research.

\section{Conflict of Interest}

The authors declared no conflict of interest. 


\section{مقالهُ يزوهشى}

\section{ارزيابى استفاده از استانداردها و اصول ارگَونومى درصنعت مبلمان ايران (مطالعه موردى: واحدهاى توليدى استان تهران)

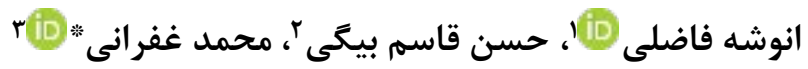

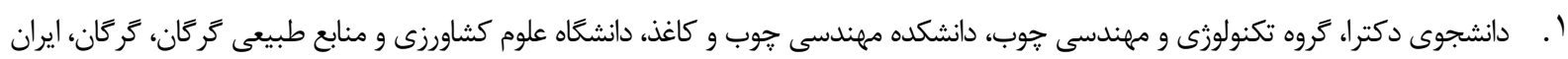

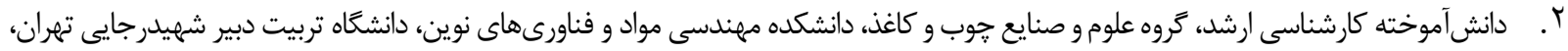

تهران، ايران

"r. استاد، تروه علوم و صنايع جوب و كاغذ، دانشكده مهندسى مواد و فناورىهاى نوين، دانشعاه تربيت دبير شهيدرجايى تهران، تهران، ايران

\begin{tabular}{|c|c|}
\hline خلاصه & اطلاعات مقاله \\
\hline 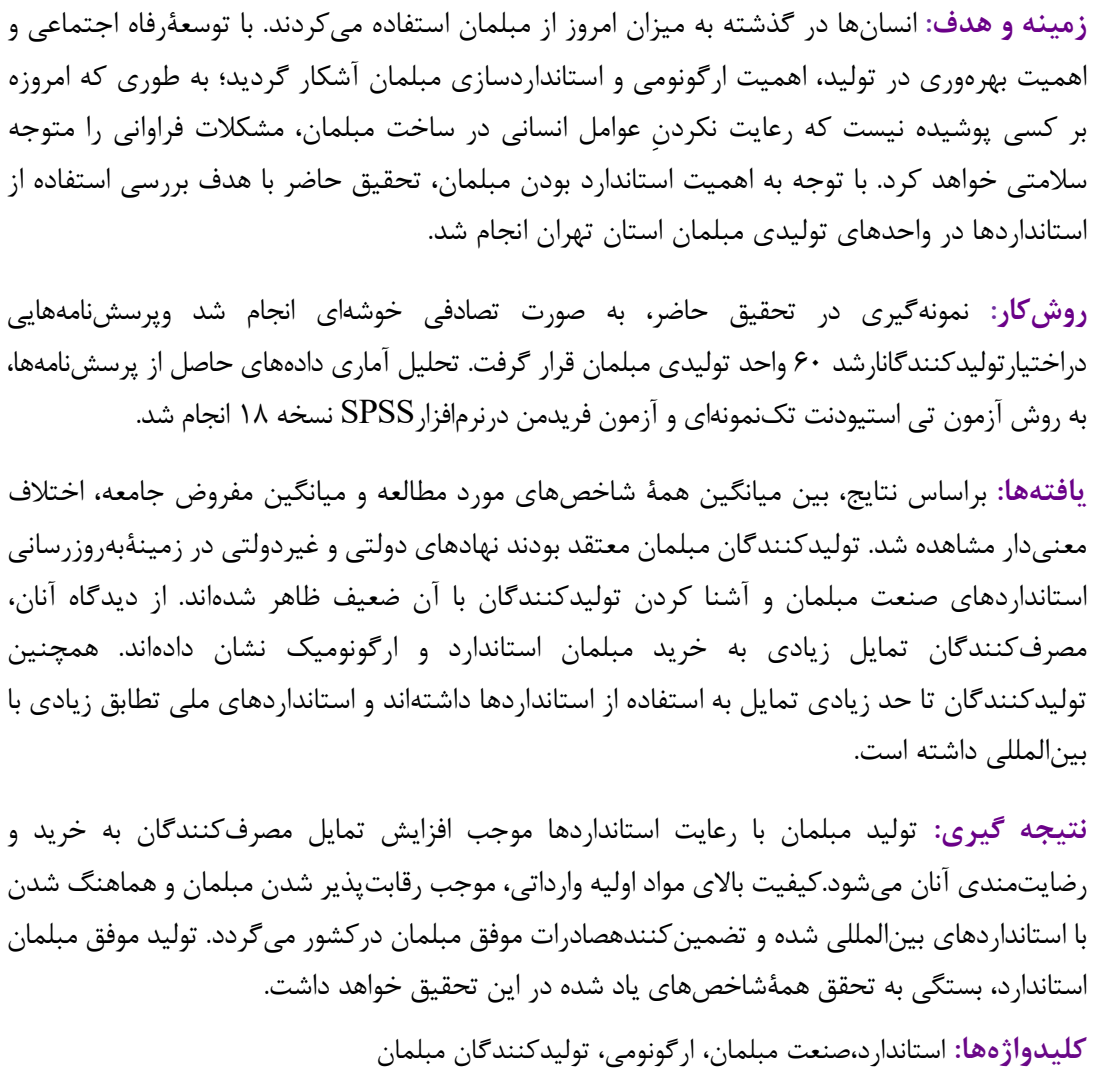 & 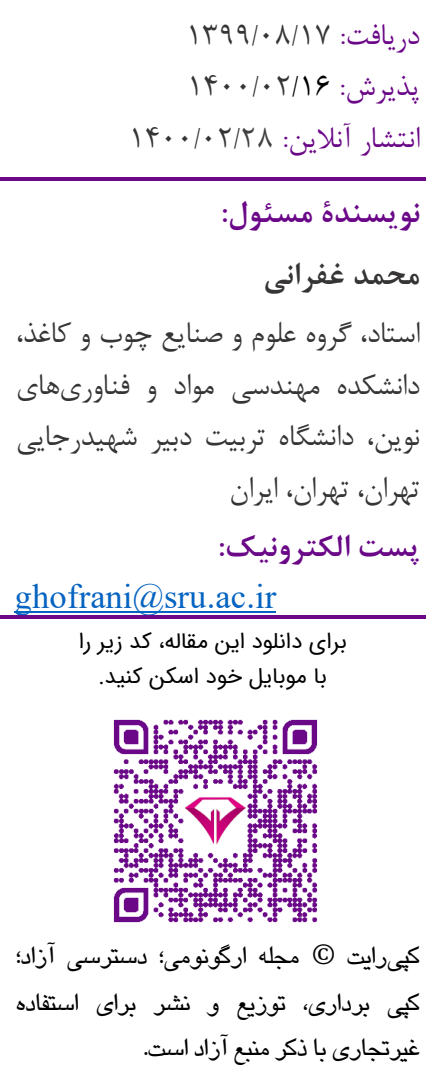 \\
\hline
\end{tabular}

مقدمه

صنعتى مبلمان با اشتغال حدود • ا هزار نفر در كشور وجود دارد

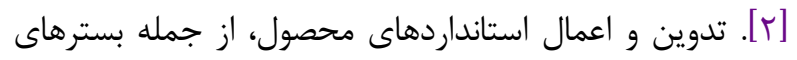
اصلى توسعه كيفيت محصول، كنترل و تضمين آن محسوب

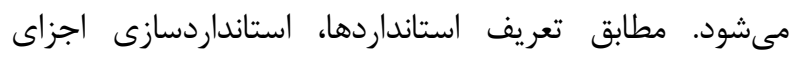
محصول و تطبيق روزآمد آن با استانداردهاى تعريف شده در

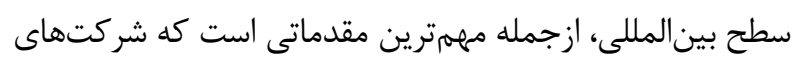

امروزه با افزايش تعداد واحدهاى توليدكننده صنعت مبلمان و افزايش عرضه اين محصولات، رقابت بين توليدكنند

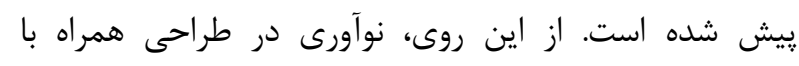

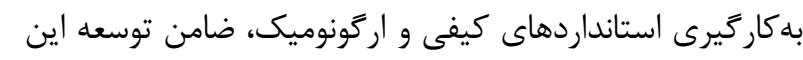

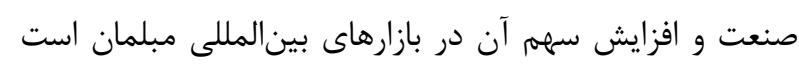

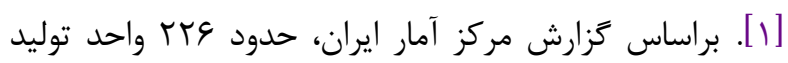


سطح كيفيت محصولات جوبى و احترام به حقوق مشتريان است

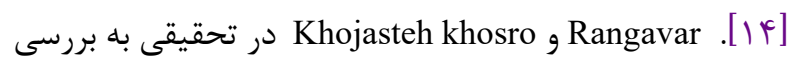
شاخصهاى موثر بر انتخاب مشترى در خريد مبلمان يرداختند.

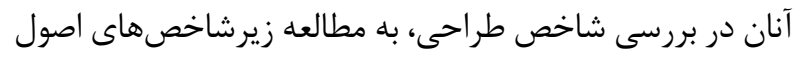

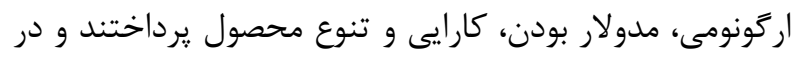

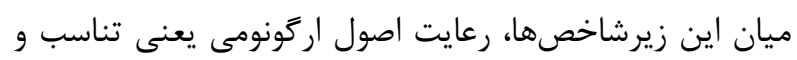

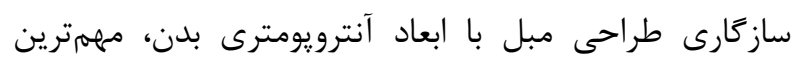

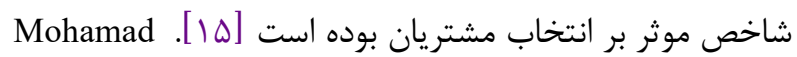
Goradi عوامل موثر بر رشد و توسعه اقتصادى صنعت مبلمان اعلام كردند شاخصهاى مديريت توليد، كيفيت محصول، عوامل

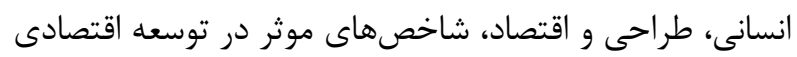

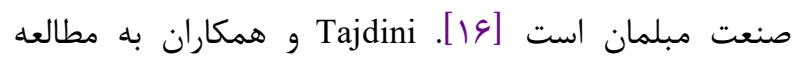
شاخصهاى موثر بر صادرات مبلمان يرداختند و به اين نتيجه

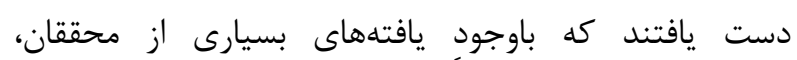
شاخصهاى دانش و مديريت، حمايت دولت از توليدكنندكان

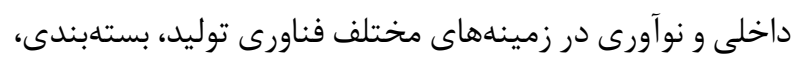
طراحى محصول و غيره به ترتيب در اولويت قرار دارند. شاخصهاى نيروى انسانى، مزيت رقابت نسبى، اقتصادى، مواد

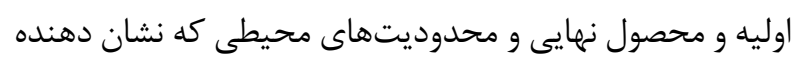

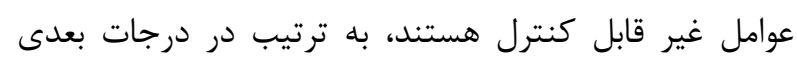

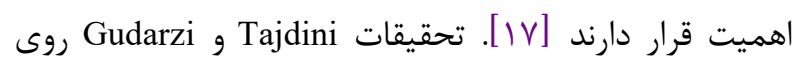
شاخصهاى موثر بر رقابتيذيرى صنعت مبلمان در ايران نشان

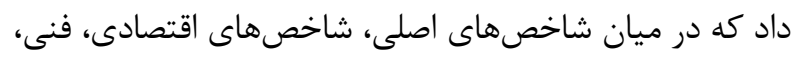

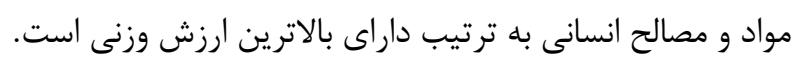
همجنين زيرشاخص طراحى موفق، نسبت به ساير زيرشاخص داريا

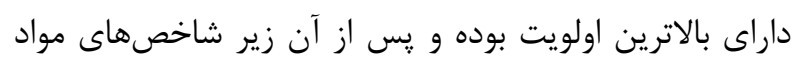
اوليه، مديريت بايدار، نيروى انسانى متخصص، توسعه استاندارد،

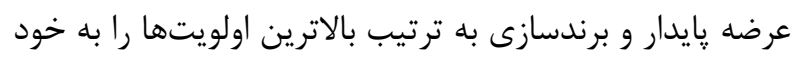

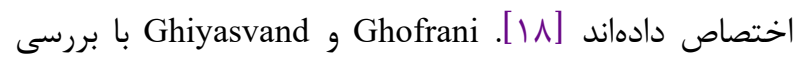
رويكرد توليدكنندكان داخلى مبلمان نشيمن در توليد و فروش إندان اين محصولات به اين نتيجه دست يافتند كه توليدكنند

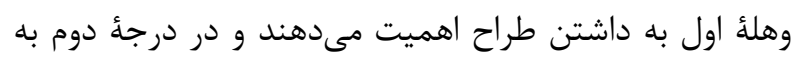

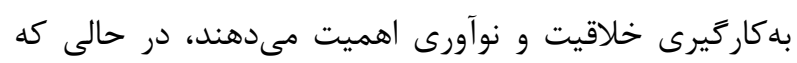

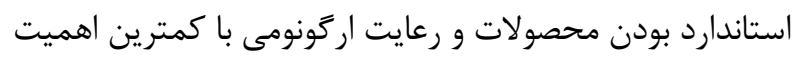

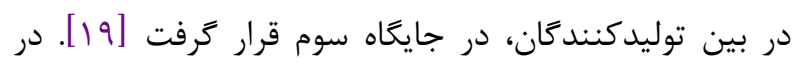

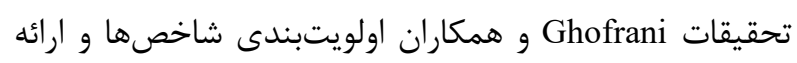

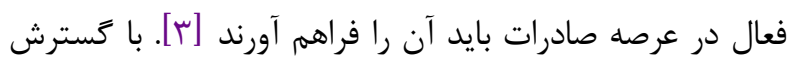

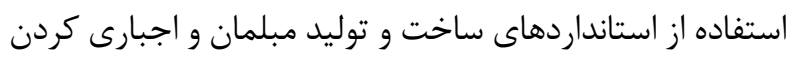

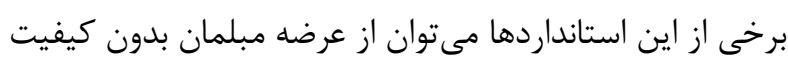

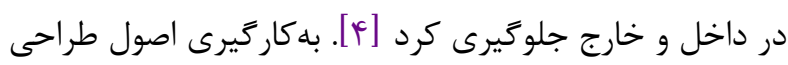

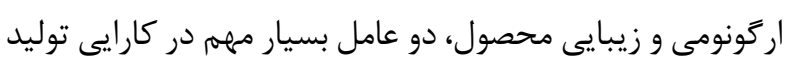

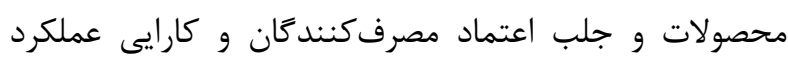

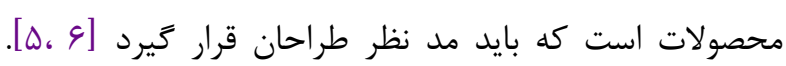

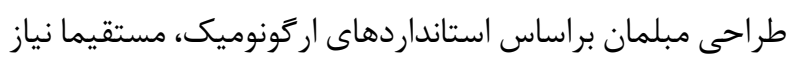

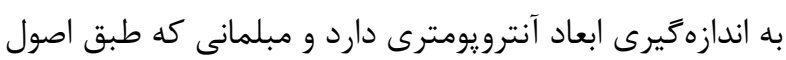

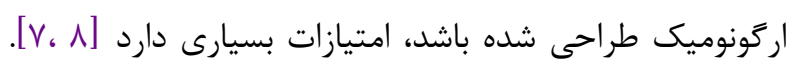

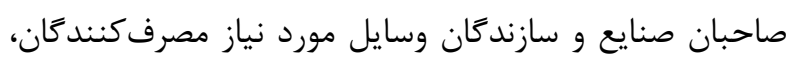

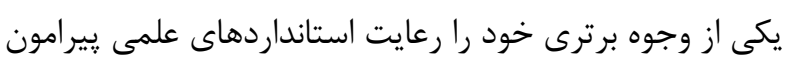

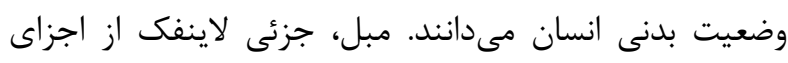

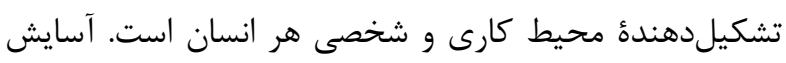

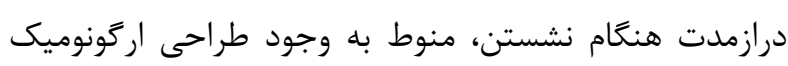

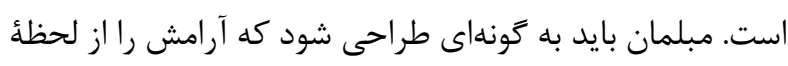

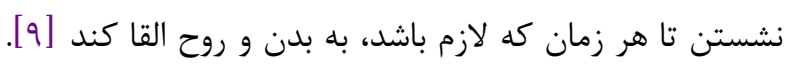

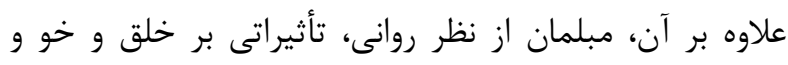

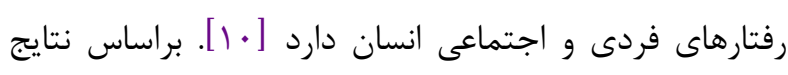

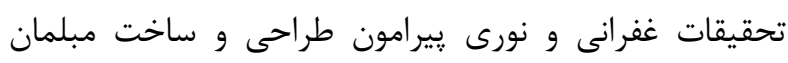

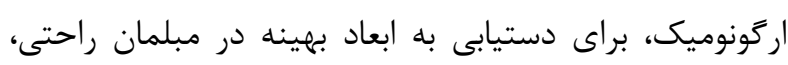

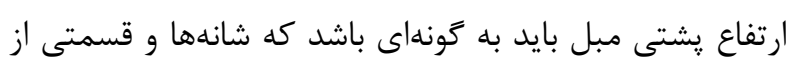

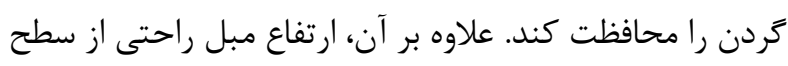

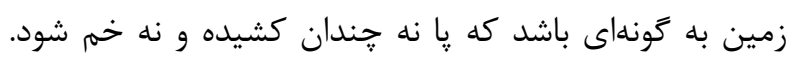

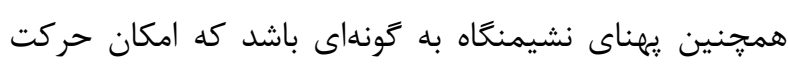

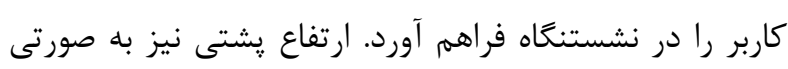

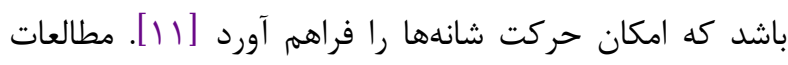
Motamedzade

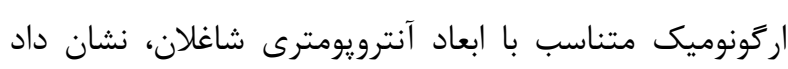

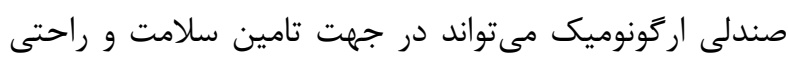
نيروى انسانى شاغل مورد استفاده قرار كيرد [1 ا I]. تحقيقات

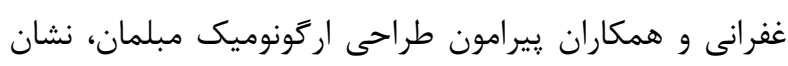

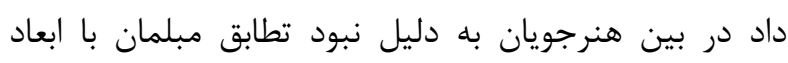

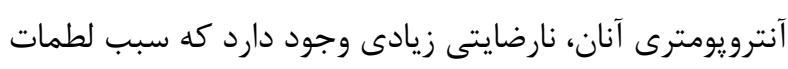

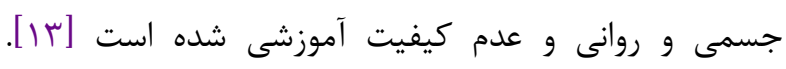

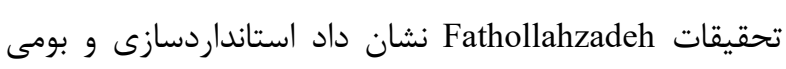

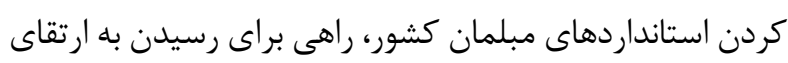


ملاك خريد مواد اوليه قرار دادن استانداردها و تمايل به

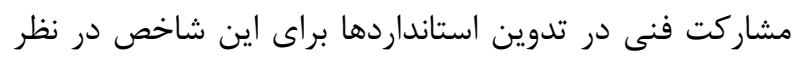
كرفته شد. شاخص جهارم، الطبيق استانداردهاى ملى با استانداردهاى

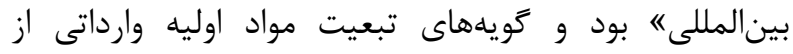

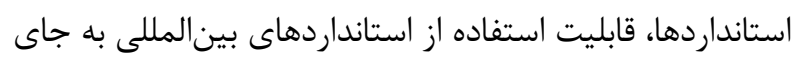

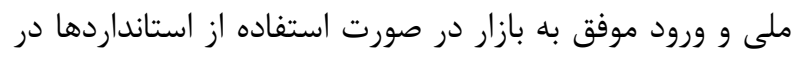

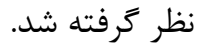

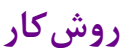

تحقيق حاضر براساس هدف، كاربردى و براساس روش،

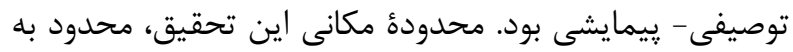
واحدهاى توليدى مبلمان استان تهران بود. اطلاعات مورد نياز

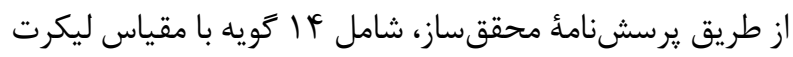
در ه طيف خيلى كم (امتياز ()، كم (امتياز Y)، متوسط (امتياز

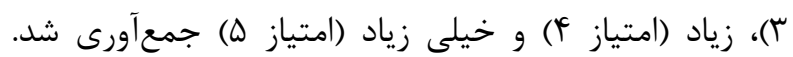

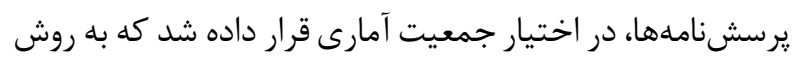

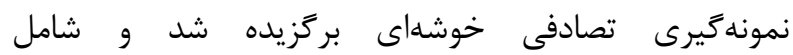
توليدكنندكان ارشد •و واحد توليدى مبلمان بود. اطلاعات

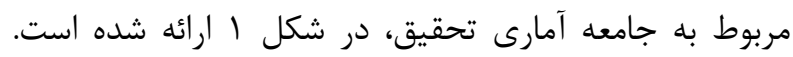

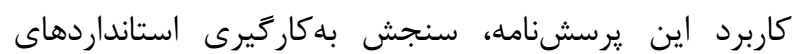
صنعت مبلمان از ديدكاه توليدكنندكان ارشد صنعت مبلمان

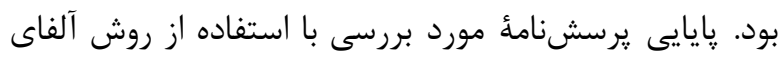

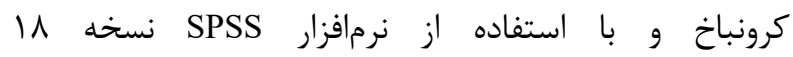
(SPSS Inc., Chicago, Ill., USA) كرونباخ، براى ارزيابى سازكارى درونى كويههاى يرسش إنامه

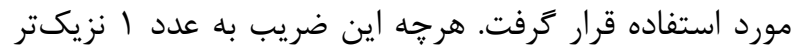

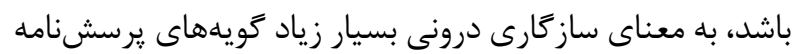

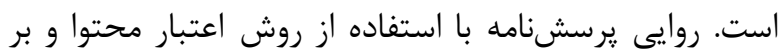

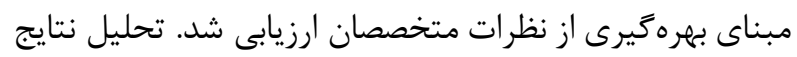

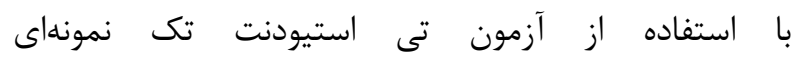
(One sample t-test)

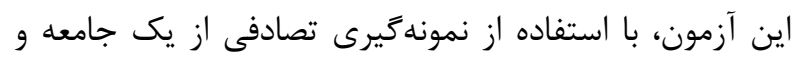

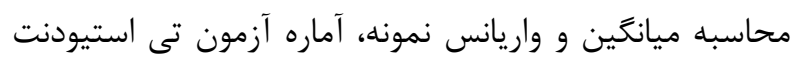
تشكيل شد و فرض صفر مورد آزمون قرار كرفت. در اين آزمون، با توجه به اين كه ديدكاه توليدكنند

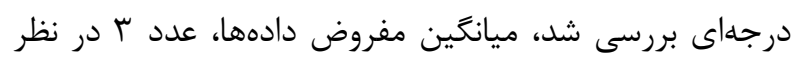

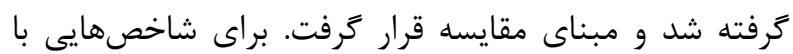

راهكارهاى تأثيركذار بر بهينهسازى مصرف جوب در ساخت

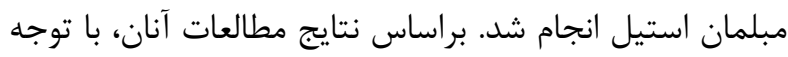

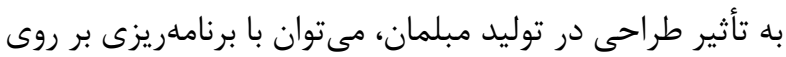
عوامل موثر در طراحى همجيون رعايت استانداردها، انتخاب

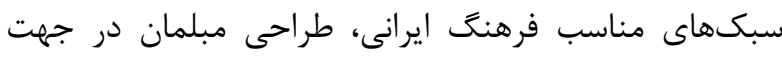

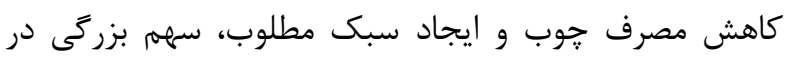

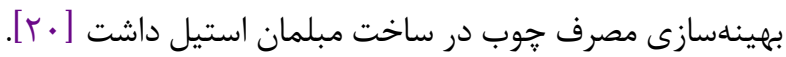
با مرور منابع مختلف پِيرامون مسائل صنعت مبلمان مشخص

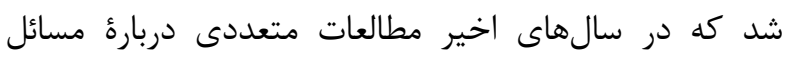

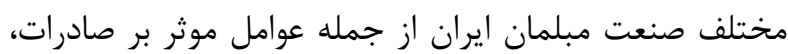

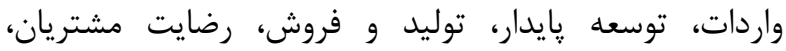

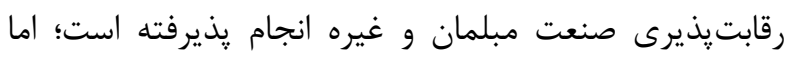

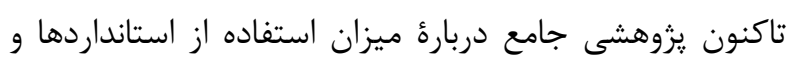
اصول اركونومى در واحدهاى توليدكننده صنعت مبلمان كشور انجام نشده است. بر اين اساس، تحقيق حاضر به دنبال ارزيابى إنى إنى

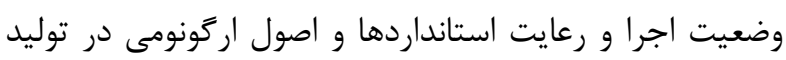
انواع مبلمان (مبلمان كلاسيك، ادارى، كابينت و غيره) از ديدكاه توليدكندكان ارشد مبلمان استان تهر ان بود.

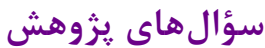

اولين شاخص مورد مطالعه در اين يرسشنامه، "ابهروزرسانى و اجراى استانداردهاى صنعت مبلمان، توسط نهادهاى دولتى و و

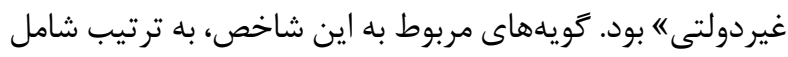
نقش نهادهاى دولتى و غيردولتى در آشنا كردن توليدكنندكان با استانداردها، ياسخكً بودن استانداردها به نيازهاى باز إرار، بهروز

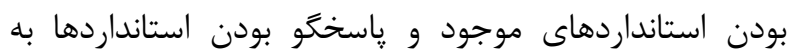
نيازهاى صنعت مبلمان در نظر كرفته شد. دومين شاخص، اتمايل مصرفكنندگان به خريد مبلمان استاندارد و اركونوميك" بود. كويههاى رضايت مصرف كنندكان إنان

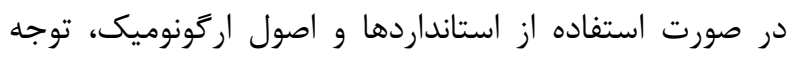
مصرفكنندكان به مبلمان استاندارد در مقايسه با ساير استانس فاكتورهاى موثر در خريد مبلمان و تعداد مصرفكنيند

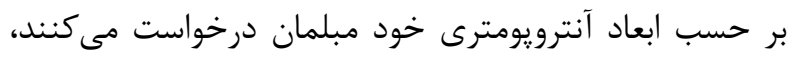
براى اين شاخص در نظر كرفته شد. سومين شاخص مورد مطالعه، اتمايل توليدكنندكان به

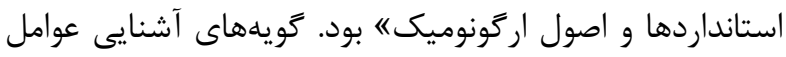

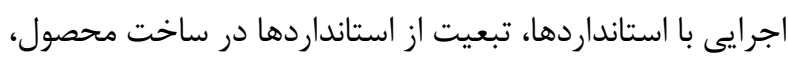


مبلمان استاندارد و ارگونوميك، شاخص تمايل توليدكنندگان به استانداردها و اصول اركونوميك و شاخص تطبيق استانداردهاى آنائ

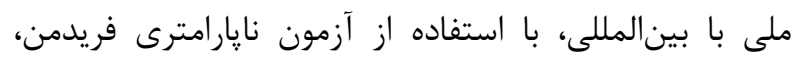
رتبهبندى شد.

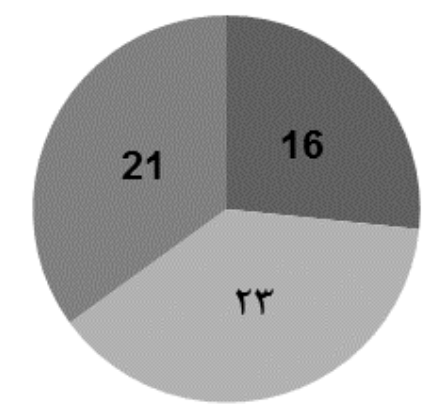

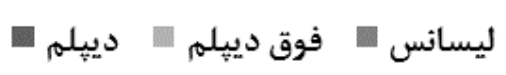

ب

شكل ا.مشخصات كلى پاسخدهندكان. الف : تعداد كاركنان واحد توليدى (نفر ) و ب : تحصيلات كاركنان واحد توليدى

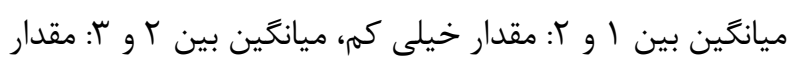

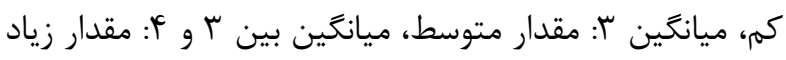

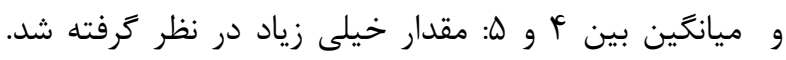

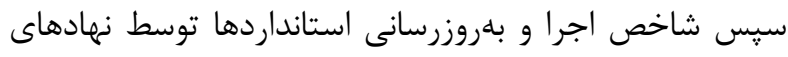
دولتى و غيردولتى، شاخص تمايل مصرفكنندكان به خروريد

بافته ها

مقدار س9191 • محاسبه شد؛ بنابراين ساز Fارى درونى يرسشنامه، مطلوب تشخيص داده شد (جدول ()). روايى :يرسشنامه با استفاده از روش اعتبار محتوا و بر مبناى بهرهزيرى از نظرات متخصصان مورد تاييد قرار زرفت.

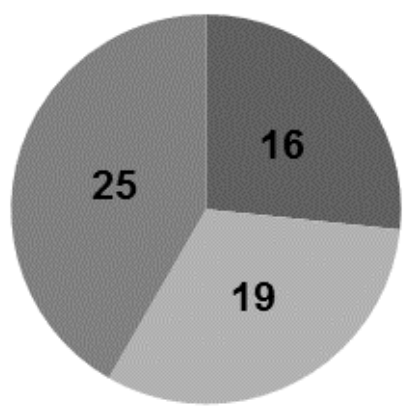

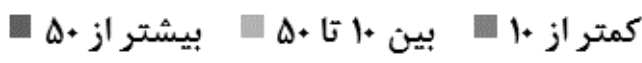

الف

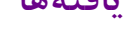

در تحقيق حاضر، ديدكاه توليدكنندگان ارشد مبلمان استان

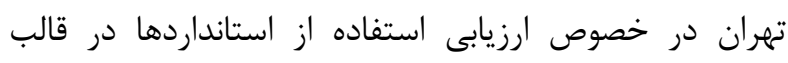
يرسشنامه بررسى شد. در ابتدا براى اندازهخيرى يايايى

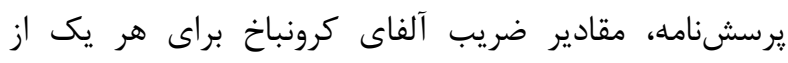

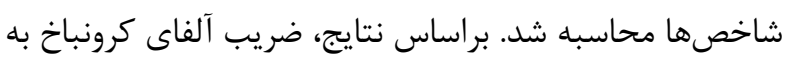

جدول ا. مقادير ضريب آلفاى كرونباخ شاخصهاى مربوط به يرسشنامه

\begin{tabular}{|c|c|c|}
\hline تويه & ضريب آلفاى كرونباخ & 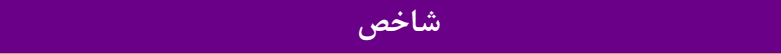 \\
\hline$r-r-r-1$ & $\cdot / 990$ & جرا و به روزرسانى استانداردها توسط نهادهاى دولتى و غير دولتى \\
\hline$V-9-\Delta$ &.$/ 911$ & تمايل مصرفكنندگان به خريد مبلمان استاندارد و اركونوميك \\
\hline $11-1 \cdot-9-1$ & $\cdot / 990$ & تمايل توليدكنند \\
\hline$|f-| r-1\}$ & $\cdot / 19 \Delta$ & تطبيق استانداردهاى ملى با بينالمللى \\
\hline
\end{tabular}

همان طور كه در جدول r مشخص شده است، به منظور

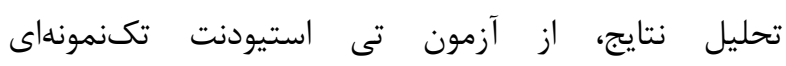
بهره گرفته شد. (One sample t-test) 


\begin{tabular}{|c|c|c|c|c|c|}
\hline \multicolumn{2}{|c|}{ فاصله اطمينان هـ٪٪ براى تفاضل } & \multirow{2}{*}{ مقدار } & \multirow{2}{*}{ درجه } & \multirow{2}{*}{ آماره تى } & \multirow{2}{*}{ 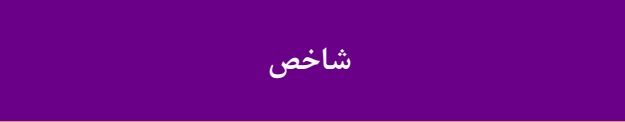 } \\
\hline 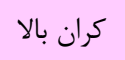 & كران ايين & & & & \\
\hline$-\cdot 19911$ & $-1 / 1 \cdot \Delta \varphi$ & $\cdot / \cdots$ & $\Delta 9$ & $-V / 9 \Delta T$ & اجرا و بهروزرسانياستانداردهاتوسط نهادهاى دولتى و غير دولتى \\
\hline . /VVGV & $\cdot / \pi \cdot 1 \cdot$ & $\cdot / \cdots$ & $\Delta 9$ & F/DTr & تمايل مصرفكنندكان به خريد مبلمان استاندارد و \\
\hline .19498 & $\cdot / T \cdot \wedge \varepsilon$ & $\cdot / \cdots$ & $\Delta 9$ & r/^৭ץ & 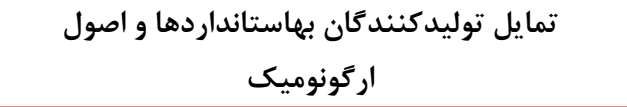 \\
\hline$\cdot 19 T \cdot V$ &.$/ T I K G$ & $\cdot 1 \cdots$ & $\Delta 9$ & $4 / \cdot \wedge \varepsilon$ & تطبيق استانداردهاى ملى با بينالمللى \\
\hline
\end{tabular}

r) و پِاسخكو بودن استانداردها به نيازهاى صنعت مبلمان (كويه

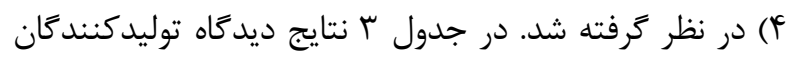

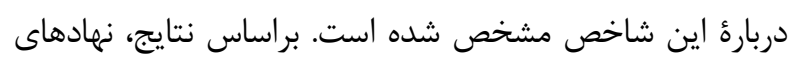

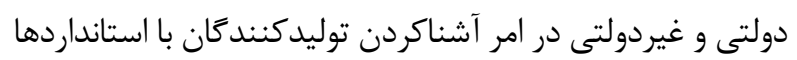

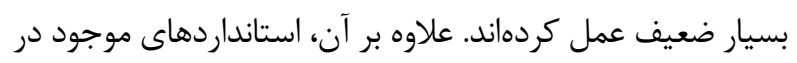

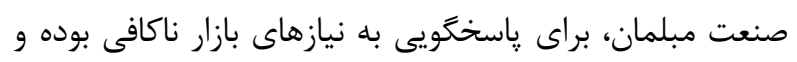

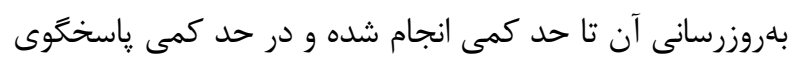

$$
\text { نيازهاى صنعت مبلمان بوده است. }
$$

شاخص هاى تحقيق

I- اجرا و بهروزرسانى استانداردهاى صنعت مبلمان توسط نهادهاى دولتى و غيردولتى إنى

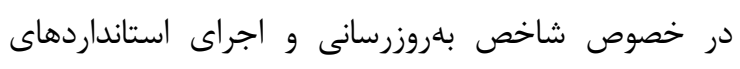

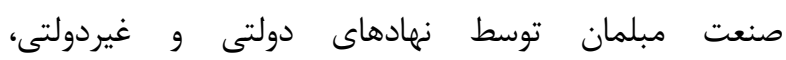

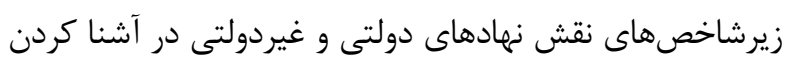

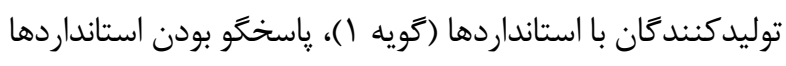

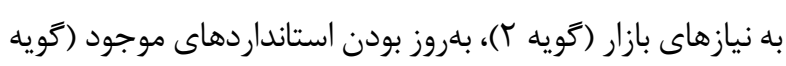

جدول r. ديدكاه توليدكنندكانمبلمان كشور درباره شاخص اول

\begin{tabular}{|c|c|c|c|c|c|c|c|c|c|}
\hline \multirow{2}{*}{ واريانس } & \multirow{2}{*}{ انحراف از } & \multirow{2}{*}{ ميانتين } & \multirow{2}{*}{ فراوانى } & \multicolumn{5}{|c|}{ فراوانى } & \multirow{2}{*}{ كويه } \\
\hline & & & & خيلى زياد & زياد & متوسط & كم & خيلى كم & \\
\hline$\cdot / 1941$ &.$/ 9 \mathrm{FV}$ & $1 / 8 \Lambda$ & q. & 1 & $r$ & $\Delta$ & 11 & rr & 1 \\
\hline$\cdot 19 \cdot r$ & -IVVG & $1 / 1$. & c. & . & r & V & $r \Lambda$ & r & $r$ \\
\hline $1 / \cdot 1 T$ & $1 / \cdot 9$ & $T / \cdot G$ & c. & r & $r$ & if & Tr & $r$. & $r$ \\
\hline$\cdot / V \Delta S$ & - /1ৎ९9 & $r / q)$ & c. & $r$ & r & TF & $r$. & 1 & $p$ \\
\hline
\end{tabular}

و بهروزرسانى استانداردهاى مرتبط با صنعت مبلمان، در حد كم كم به وظيفه خود عمل مى كنند.

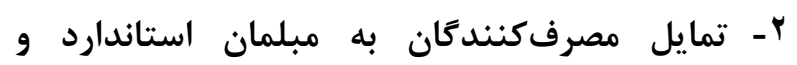

\section{ارَّونوميك}

در خصوص شاخص تمايل مصرفكنندكان به مبلمان استاندارد و اركونوميك، زيرشاخصهاى رضايت مصرفكنيند در صورت استفاده از استانداردها و اصول ارگونوميك (گويه ه)، توجه مصرفكنندگان به مبلمان استاندارد در مقايسه با ساير

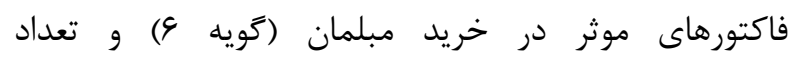
مصرفكنندگانى كه بر حسب ابعاد آنترويومترى خود مبلمان

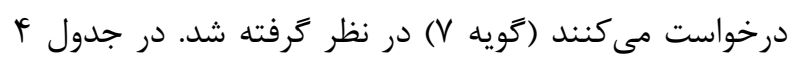

براساس نتايج، ميانگين كلى ديدگاه توليدكنندگان در

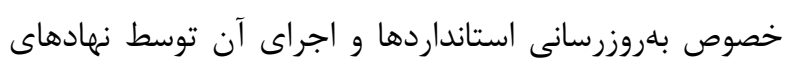

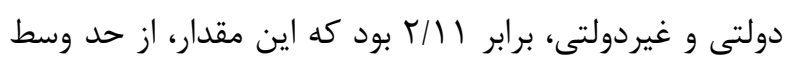
مقياس ليكرت (عدد ب) كمتر است. براساس جدول بـ ب، از آنجايى كه مقدار احتمال (Sig.) در خصوص شاخص بلهروزرسانى و

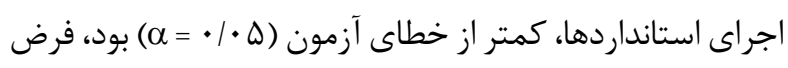

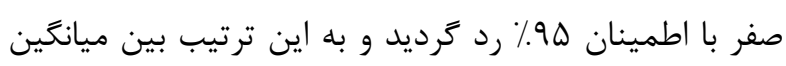

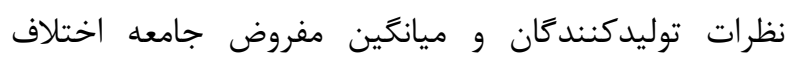
معنى دار وجود داشت. به طور كلى مى توان نتيجه كرفت كه از نظر توليد كنند كان، نهادهاى دولتى و غيردولتى در زمينـة اجرا 
استاندارد در مقايسه با ساير فاكتورهاى موثر در خريد مبلمان

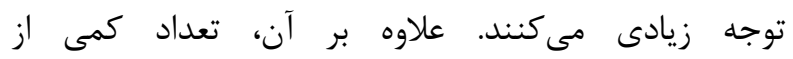

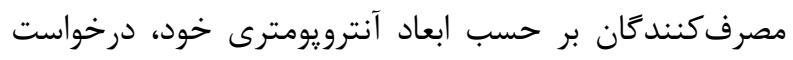
مبلمان مى كنند.
نظر توليدكنندكان دربارة اين شاخص مشخص شده است.

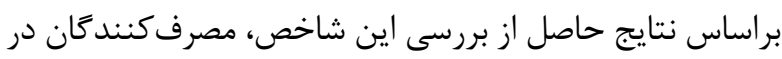

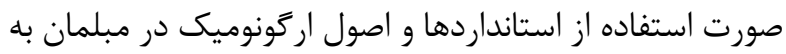

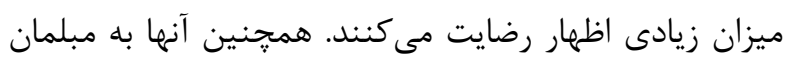

جدول F. ديدكاه توليدكنندگانمبلمان كشور درباره شاخص دوم

\begin{tabular}{|c|c|c|c|c|c|c|c|c|c|}
\hline \multirow{2}{*}{ واريانس } & \multirow{2}{*}{ انحراف از } & \multirow{2}{*}{ ميانگين } & \multirow{2}{*}{ فراوانى } & \multicolumn{5}{|c|}{ فراوانى } & \multirow{2}{*}{ كَويه } \\
\hline & & & & خيلى زياد & زياد & متوسط & كم & خيلى كم & \\
\hline$\cdot 10 \wedge 9$ & - IVAV & r/VG & q. & V & rq & If & $r$ & 1 & $\Delta$ \\
\hline - |AgF & .1949 & $r / 91$ & q. & 11 & rᄉ & 11 & 1 & r & 9 \\
\hline$|/ \Delta F|$ & $|/ T F|$ & r/A & c. & f & $r \cdot$ & 1. & 19 & 1. & $V$ \\
\hline
\end{tabular}

اجرايى با استانداردها (كويه ^)، استفاده از استانداردها در

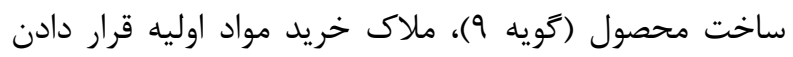

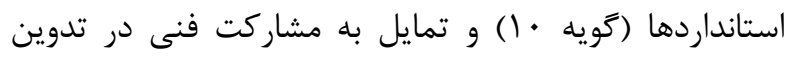

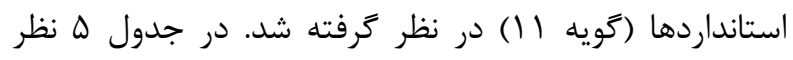

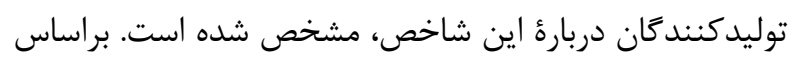

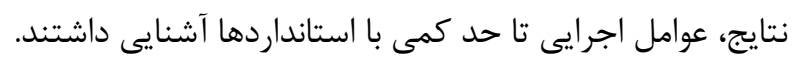

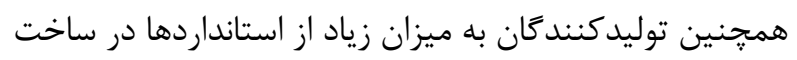

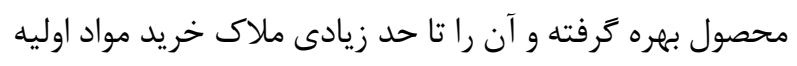

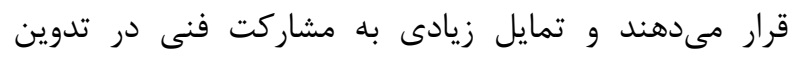

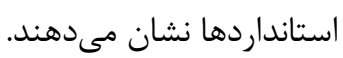

نتايج نشان داد ميانكين كلى شاخص تمايل مصرف كنندگان

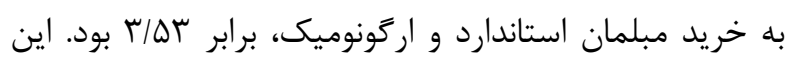

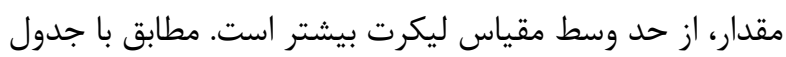

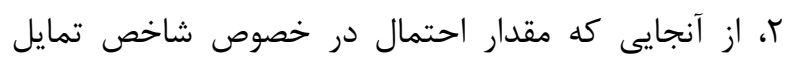

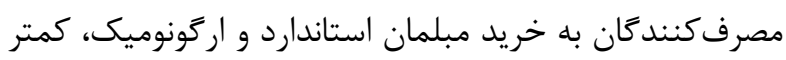

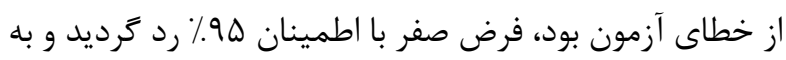

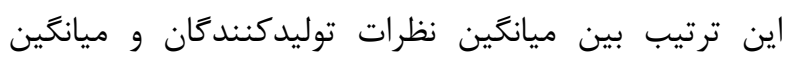

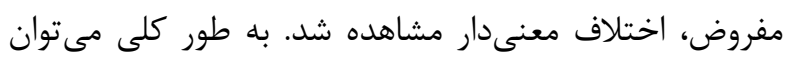

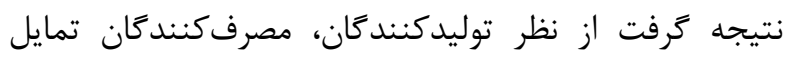

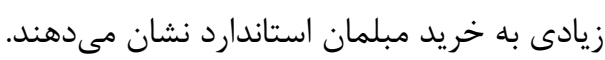

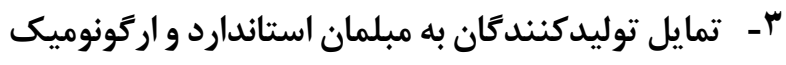
در خصوص شاخص عمل به استانداردها و توجه به اصول

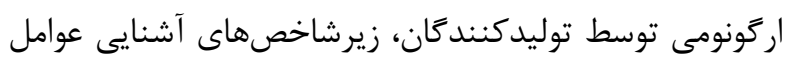

جدول ه. ديدًَاه توليدكنندكانمبلمان كشور درباره شاخص سوم

\begin{tabular}{|c|c|c|c|c|c|c|c|c|c|}
\hline \multirow{2}{*}{ واريانس } & \multirow{2}{*}{ انحراف از } & \multirow{2}{*}{ ميانگين } & \multirow{2}{*}{ فراوانى } & \multicolumn{5}{|c|}{ فراوانى } & \multirow{2}{*}{ تويه } \\
\hline & & & & خيلى زياد & زياد & متوسط & كم & خيلى كم & \\
\hline $1 / \cdot 9$ & $1 / \cdot r$ & r/99 & 4. & r & V & TF & 19 & V & $\wedge$ \\
\hline - /Aqf & .1949 & $r / \Delta$. & q. & 1 . & IV & $r V$ & $\Delta$ & 1 & 9 \\
\hline - IATE & $\cdot 19 \cdot 1$ & r/Dq & q. & $1 \cdot$ & $r \cdot$ & $r \Delta$ & F & 1 & 1. \\
\hline - IDTD & - NYY & $r / 91$ & c. & it & rᄉ & V & r & . & 11 \\
\hline
\end{tabular}

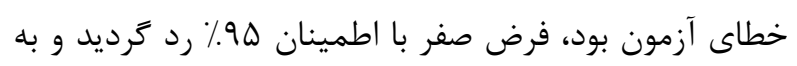

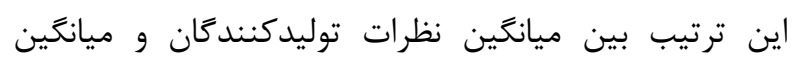

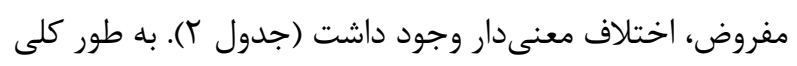

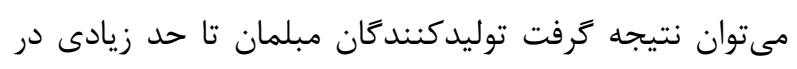

نتايج نشان داد ميانگين كلى ديدكاه توليدكنندگان در اردان

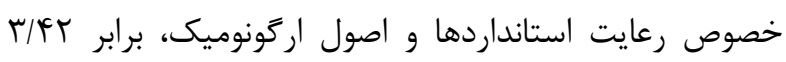

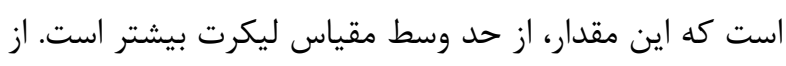

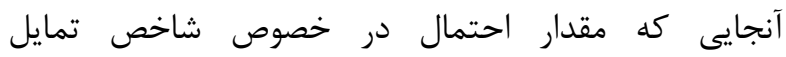
توليدكنندكان به استانداردها و اصنهال درل اركونوميك، كمتر از 
بينالمللى به جاى ملى (كويه س (1) و ورود موفق به بازار در صورت

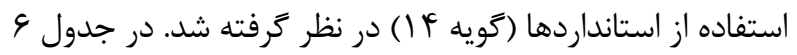
ديدكاه توليدكنندكان دربارة اين شاخص مشخص شده است.

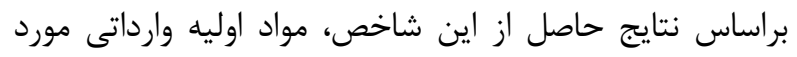
استفاده در ساخت مبلمان تا حد كمى از استانداردها تبعيت كرده إنا

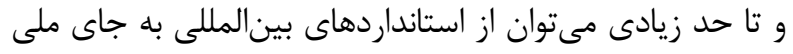

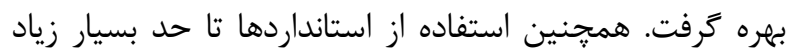
موجب ورود موفق به بازار مىشود.
به كاركيرى استانداردها در توليد محصولات، به وظيفه خود عمل

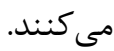

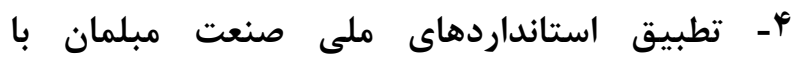
استاندار دهاى بين المللى تصئى

در خصوص شاخص تطبيق استانداردهاى ملى با استانداردهاى

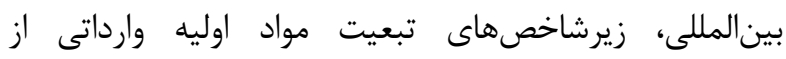

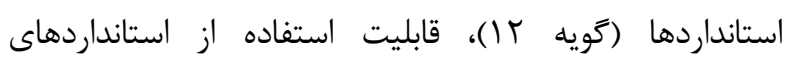

جدول 9. ديدًاه توليدكنندكانمبلمان كشور درباره شاخص جهارم

\begin{tabular}{|c|c|c|c|c|c|c|c|c|c|}
\hline \multirow{2}{*}{ واريانس } & \multirow{2}{*}{ انحراف از } & \multirow{2}{*}{ ميانَين } & \multirow{2}{*}{ فراوانى } & \multicolumn{5}{|c|}{ فراوانى } & \multirow{2}{*}{ تويه } \\
\hline & & & & خيلى زياد & زياد & متوسط & كم & خيلى كم & \\
\hline - $/ \Lambda \Delta V$ &.$/ 9 Y \Delta$ & $T / F \mid$ & q. & 1 & $r$ & rA & 19 & Ir & $\pi$ \\
\hline I/ITY & $1 / \cdot \Delta q$ & $r / T \Lambda$ & द. & 9 & If & $r \Delta$ & 9 & r & זו \\
\hline -/TAS & $\cdot / \Delta K F$ & $F / \Delta \omega$ & 4. & MF & ra & 1 & $\cdot$ & . & if \\
\hline
\end{tabular}

معنىدار مشاهده شد (جدول ؟). به طور كلى مىتوان نتيجه

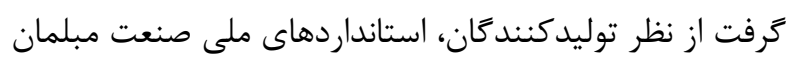
مطابقت زيادى با استانداردهاى بين المللى دارند.

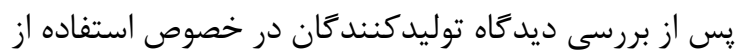

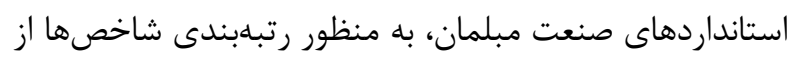
آزمون نايارامترى فريدمن بهره كَرفته شد.
نتايج نشان داد ميانكين كلى ديدكاه توليدكنندكان در

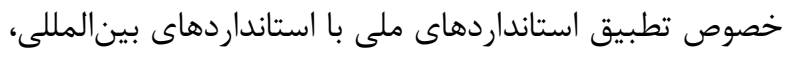

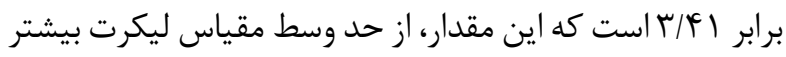

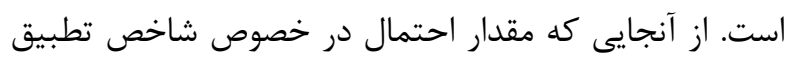

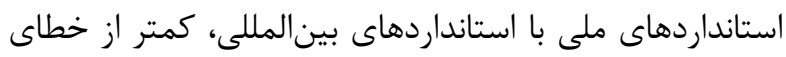

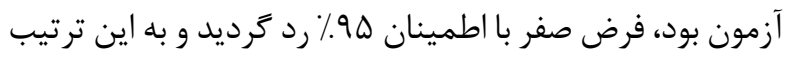

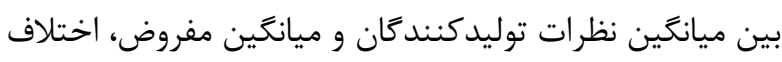

جدول V. آماره آزمون رتبهبندى فريدمن

\section{مقدار احتمال}

$\cdot / \cdots$

\section{مربع كاى}

$1 \pi \pi / 11$.
تعداد

c.
رد فرض صفر داده شد. بنابراين با اطمينان ه9٪ از ديدگاه

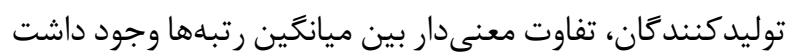

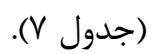

بر طبق نتايج رتبهبندى شاخصهاى مورد مطالعه، مقدار

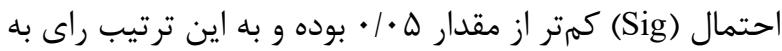

جدول ^. رتبدبندى شاخصها از ديدكًاه توليدكنندكان

\begin{tabular}{|c|c|c|}
\hline 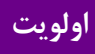 & ميانگين رتبه & شاخصها \\
\hline f & $1 / \cdot 1$ & اجرا و به روزرسانى استانداردها توسط نهادهاى دولتى و غير دولتى \\
\hline 1 & $r / T$ & تمايل مصرفكنندكان به خريد مبلمان استاندارد و اركونوميك \\
\hline r & r/AF & تمايل توليدكنندكان به استانداردها و اصول اركونوميك \\
\hline r & r/A & تطبيق استانداردهاى ملى با بينالمللى \\
\hline
\end{tabular}


فقدان توسعه و بلهروزرسانى استانداردهاى بين المللى و عدم توجه جدى به مقوله تحقيق و توسعه در واحدهاى اين صنعت،

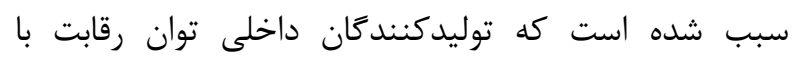

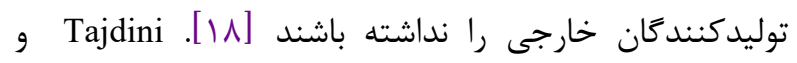

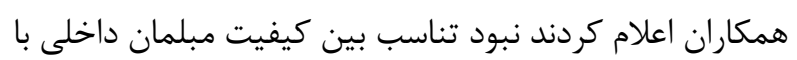

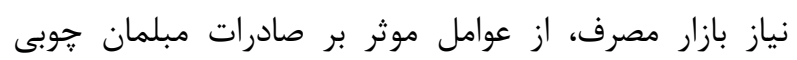

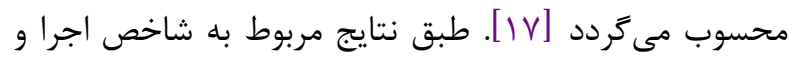

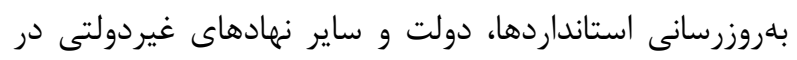

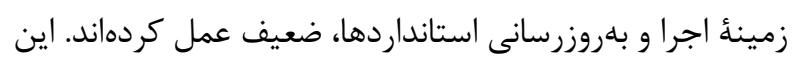

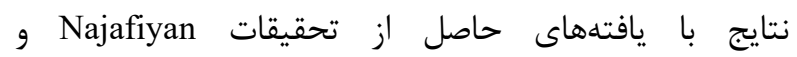
Aghababaei

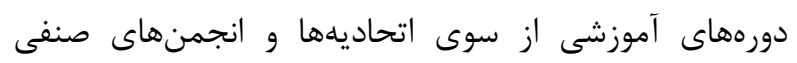

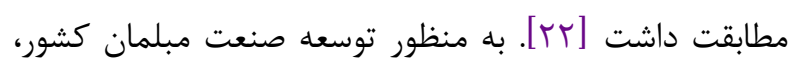

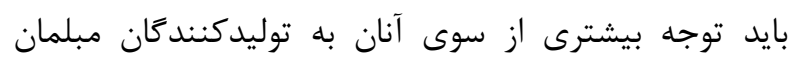

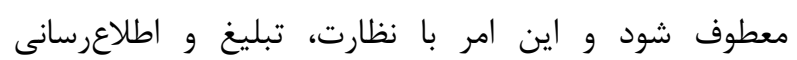

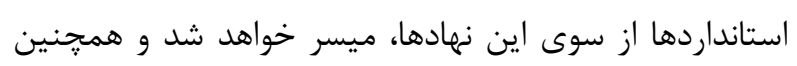
ضرورى است كه بهروزرسانى و تطبيق استانداردها با نيازهاى

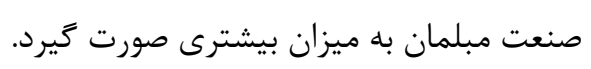

\section{تمايل مصرفكنندكان به خريد مبلمان استاندارد و}

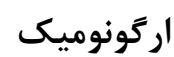

در بازاريابى نوين، مشترىمدارى و توجه به رضايت مشتريان

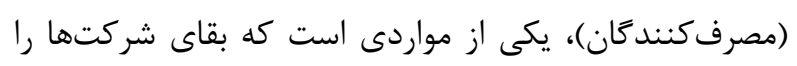

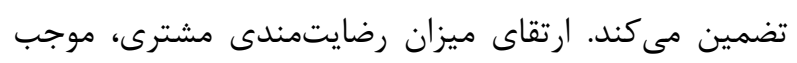

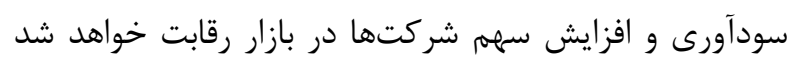

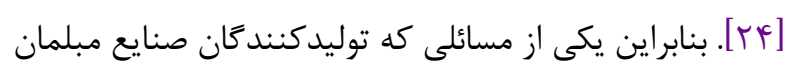

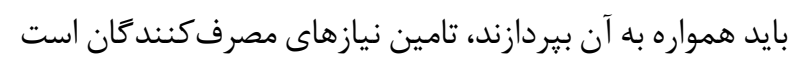

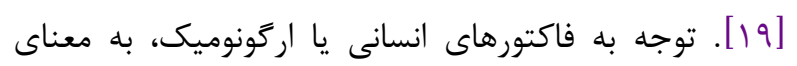

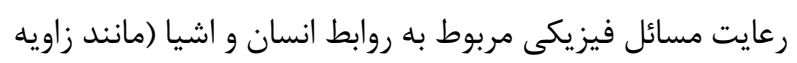

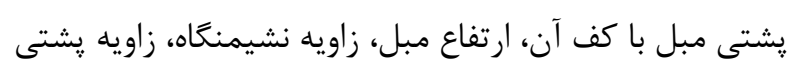

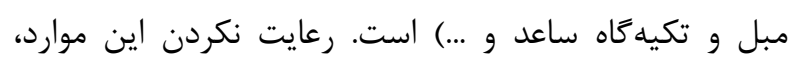

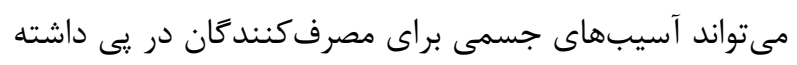

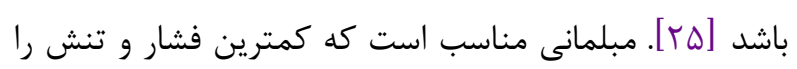

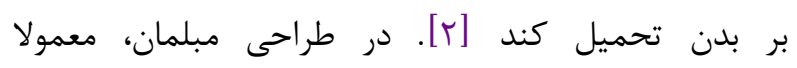

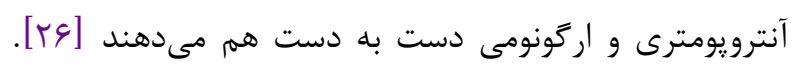
مhiyasvand و Ghofrani مبلمان، جلب رضايت مشترى را مههمترين عامل تأثيركذار در

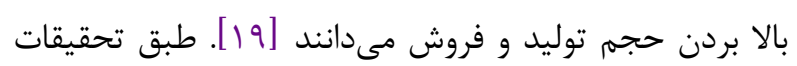

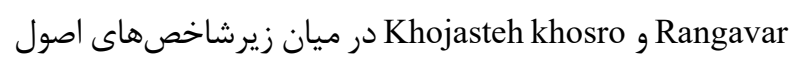

مطابق با نتايج به دست آمده، رتبؤ اول مربوط به شاخص

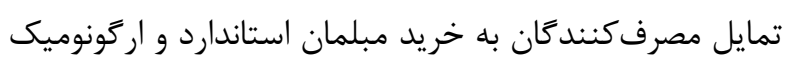

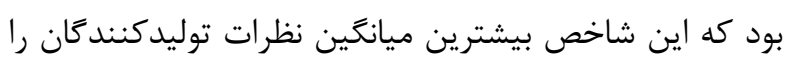

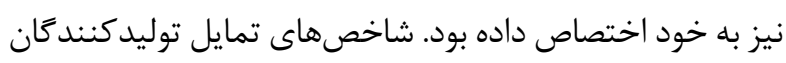

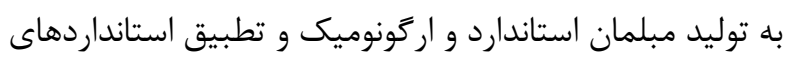

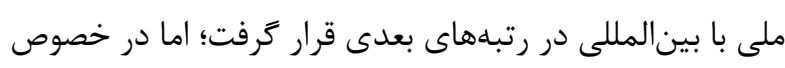

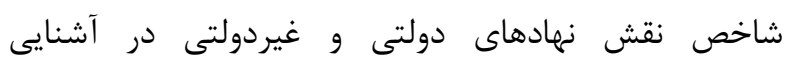

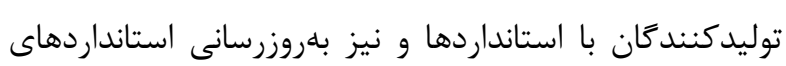

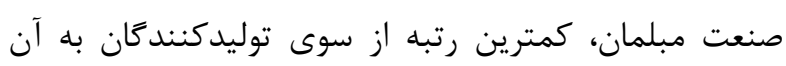

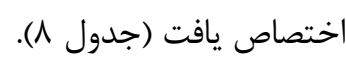

بحث

\section{اجرا و بهروزرسانى استانداردها توسط نهادهاى دولتى}

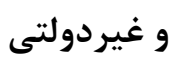

تبليغات، قدرتمندترين ابزار شناساندن شركتها، كالاها،

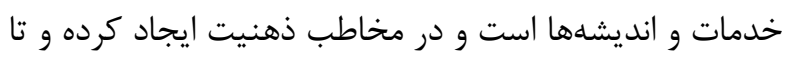

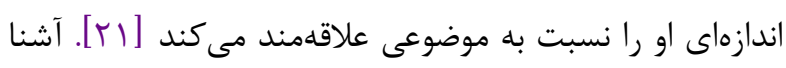

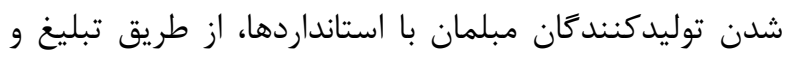

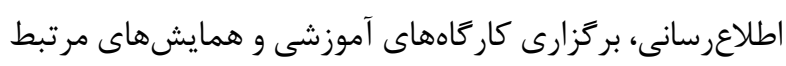

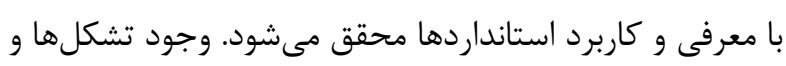

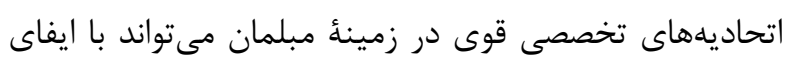

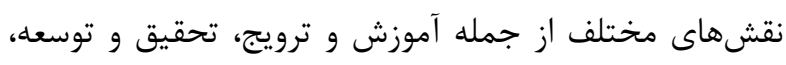

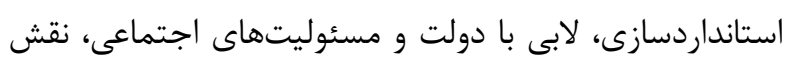

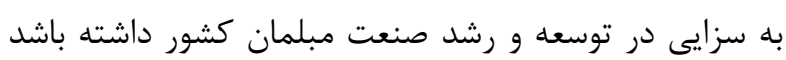

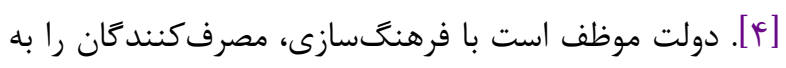

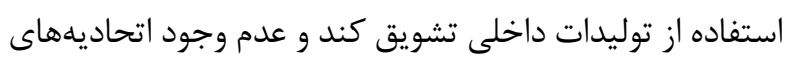
قدرتمند صنفى در حمايت از توليدكنندًان و و عدم حمان حمايت

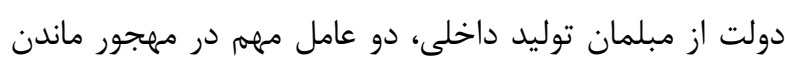

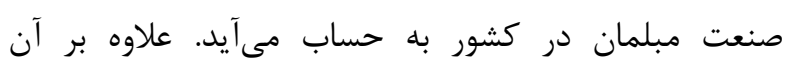

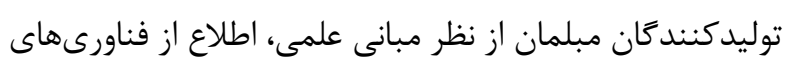

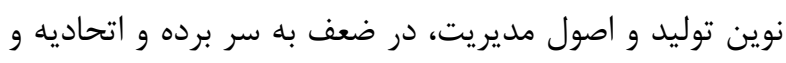

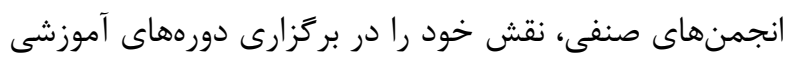

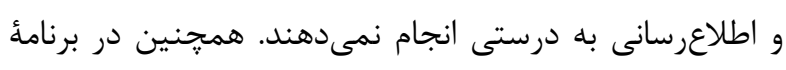

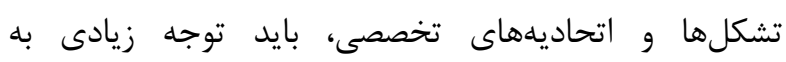

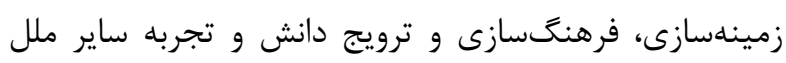

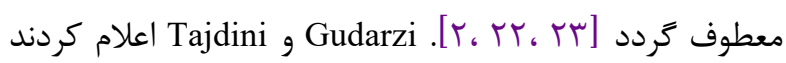

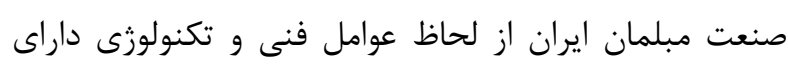
مشكلات بسيارى است. عدم استفاده از فناورىهاى إن جديد فيد، 


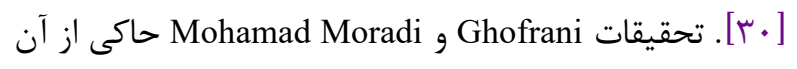

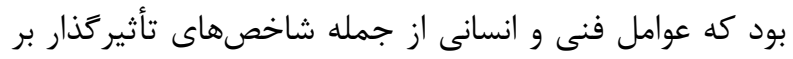

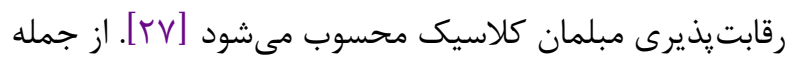

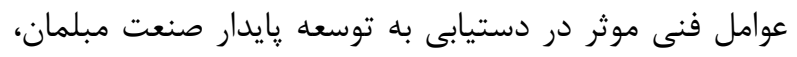

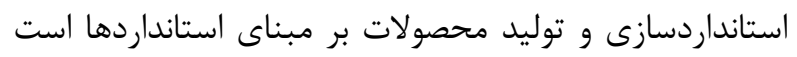

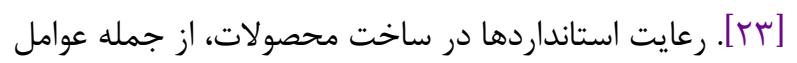

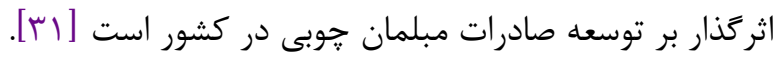

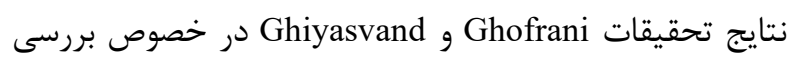
ديدكاه توليدكنند

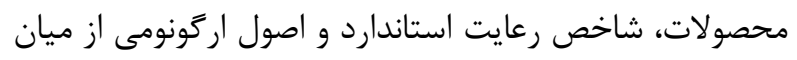

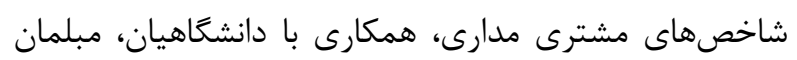

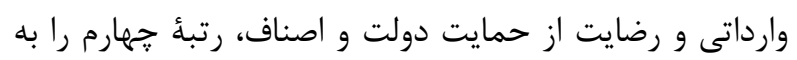

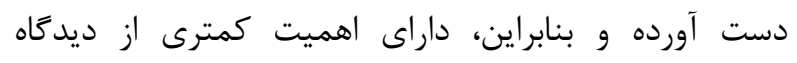

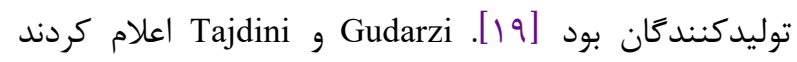
شاخصهاى تكنولوزى پيشرفته، تحقيق و توسعه، توسعه

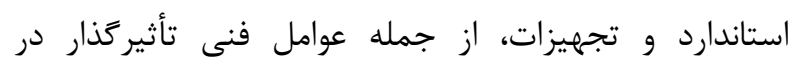

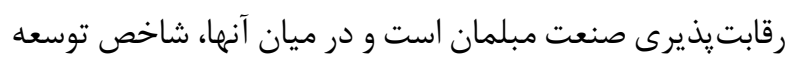

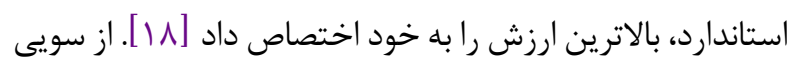

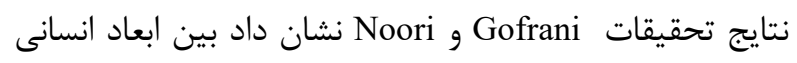
بومى و مبلمان موجود در بازار تفاوت زيادى وجود دارد. اين امر،

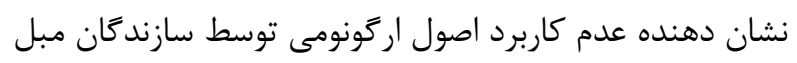

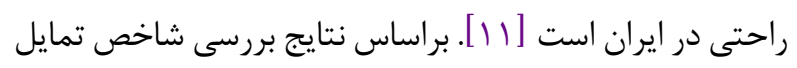

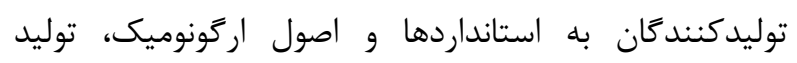

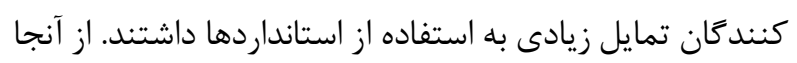

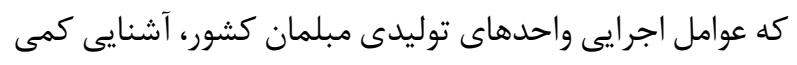

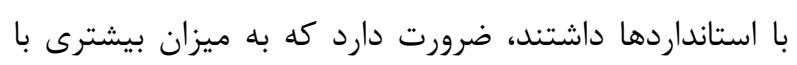

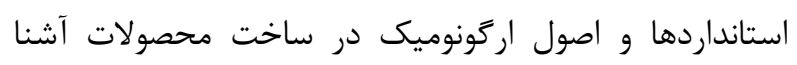

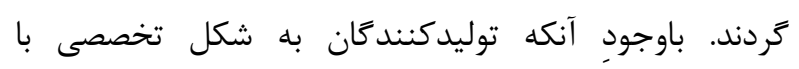

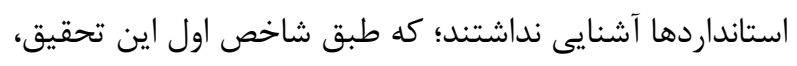

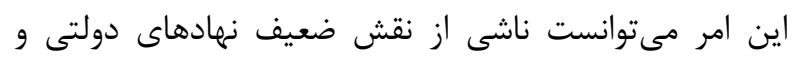

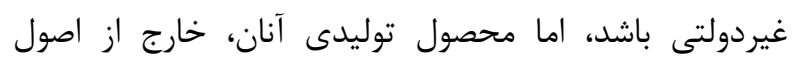

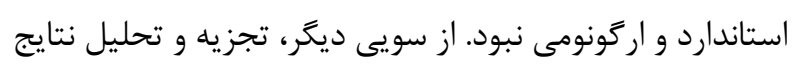

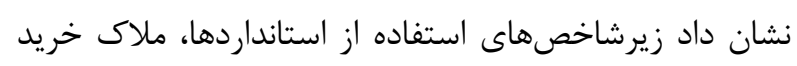

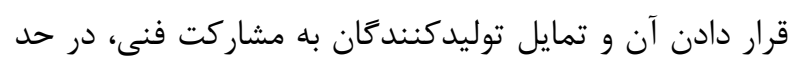
مطلوبى بوده است.

\section{تطبيق استانداردهاى ملى با بينالمللى}

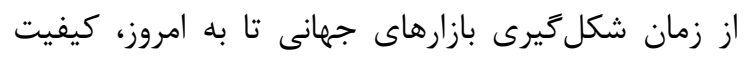

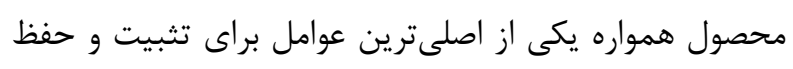

اركونومى، مدولار بودن، كارايى و تنوع محصول، زيرشاخص

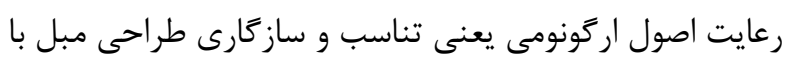

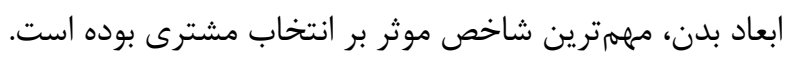

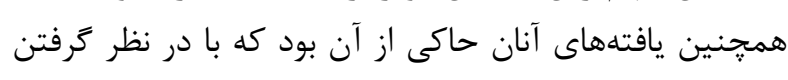

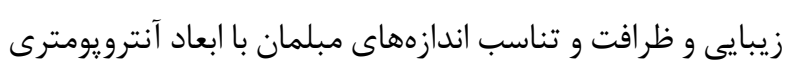

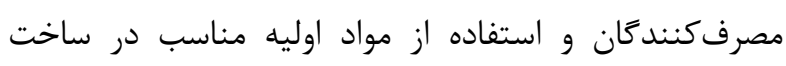

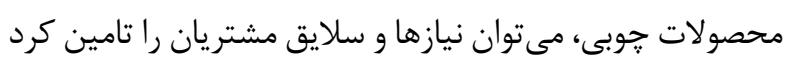

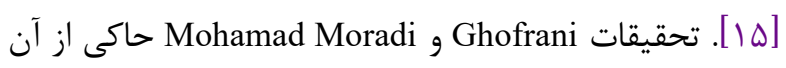

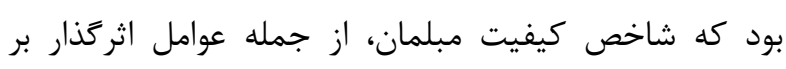

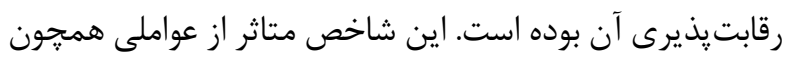

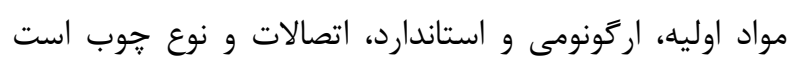
[Tr]

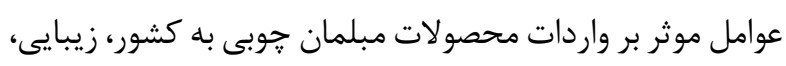

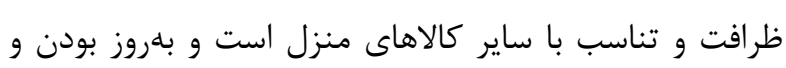

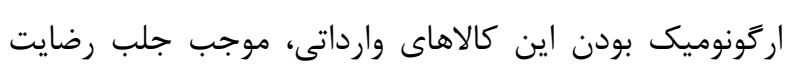

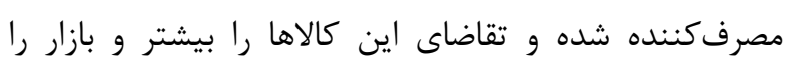

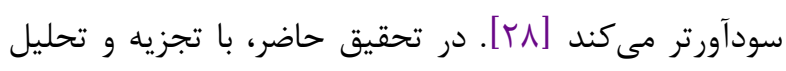

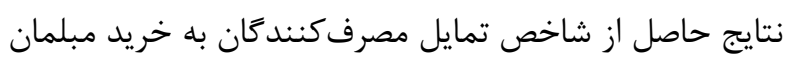

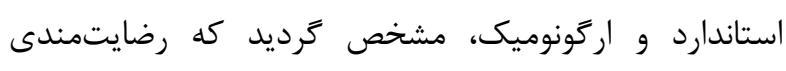

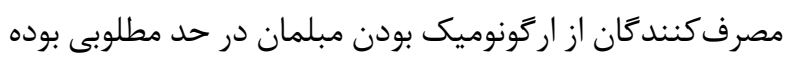

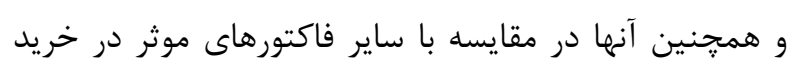

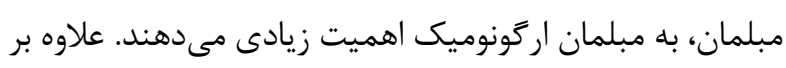

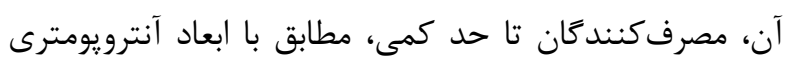

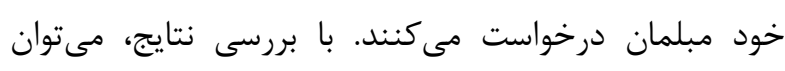

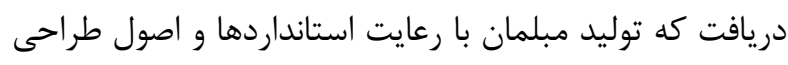

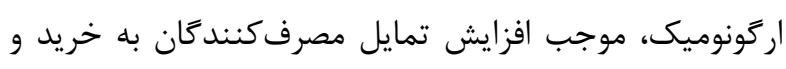

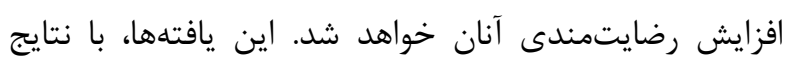

تحقيقات Ghofrani و Ghiyasvand مطابقت داشت [9 19 ].

\section{تمايل توليدكنندًان به استانداردها و اصول اركونوميك} يكى از تنكَناهاى اصلى صنعت مبلمان، نبود نيروى كار ماهر

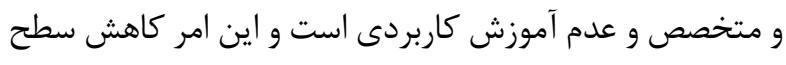

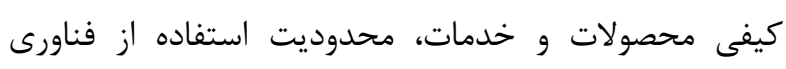

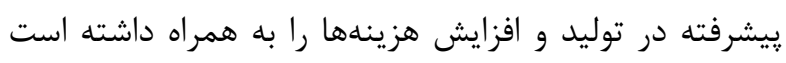

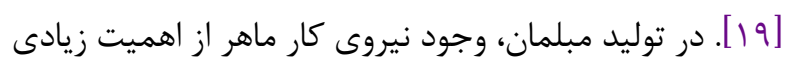

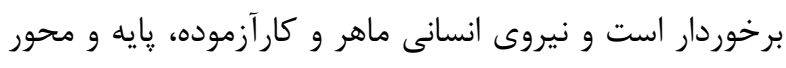

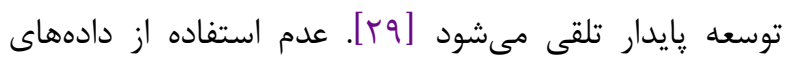

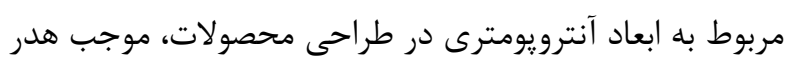

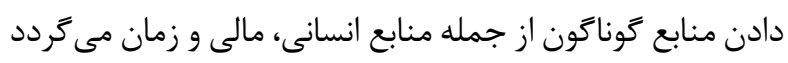


كردد. نتايج تحقيقات Alizadeh و همكاران و تحقيقات ضيايى نيز مويد اين امر بود [اس، سب].

\section{رتبدبندى شاخصها}

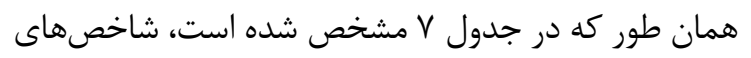

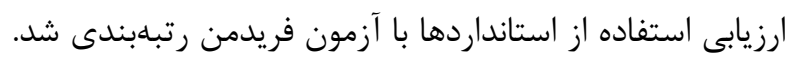

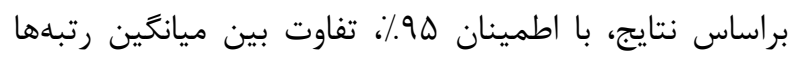

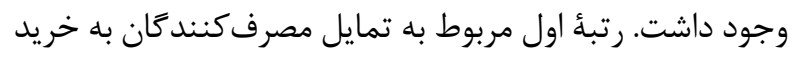
مبلمان استاندارد و اركونوميك بود؛ به ائ اين معنا كه از ديد ديداه

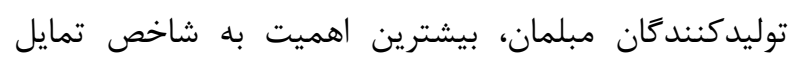

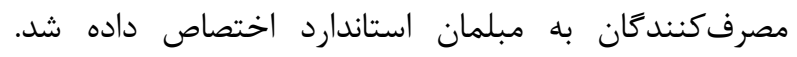

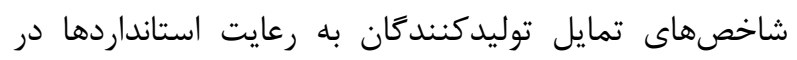

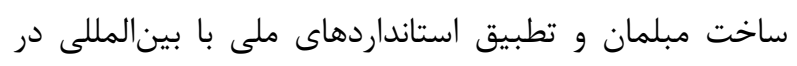

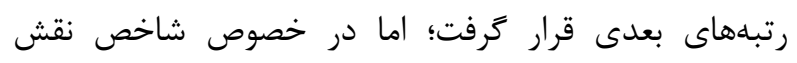

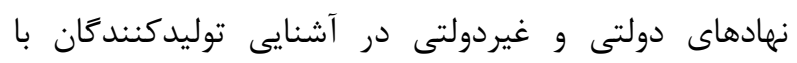

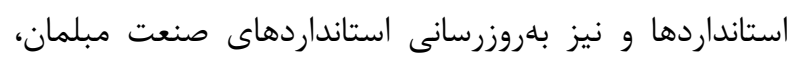

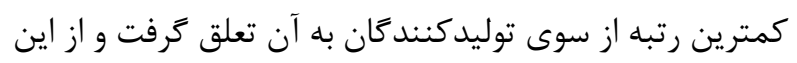
روى نياز به توجه بيشترى در اين زمينه است؛ زيرا توليد موفق إن تئن

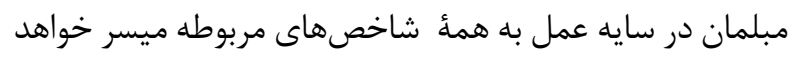

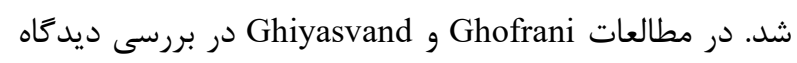
توليدكنند داده شد كه شاخصهاى مشترىمدارى، همكارى با دانشعاهيان،

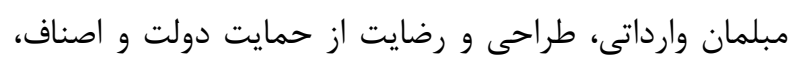

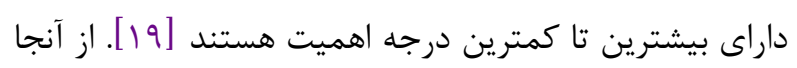

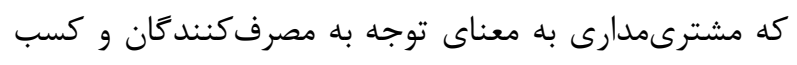

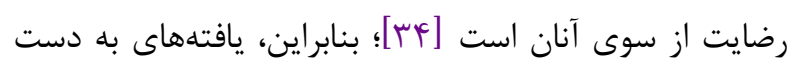

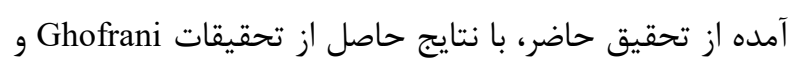

Ghiyasvand

\section{نتيجه كيرى}

در تحقيق حاضر به ارزيابى استفاده از استانداردها در واحدهاى

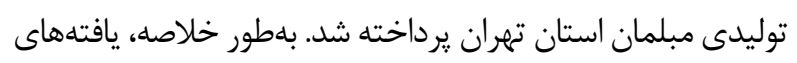

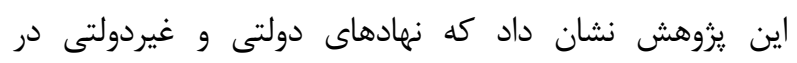

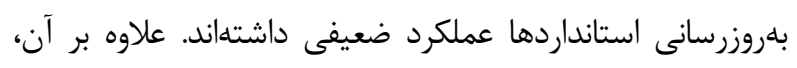
مصرفكنندكان، تمايل زيادى به خريد مبلمان استاندارد نشان

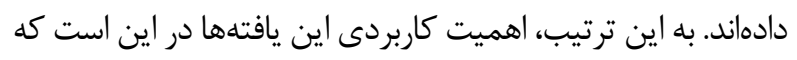

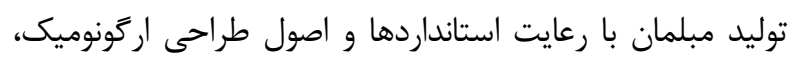

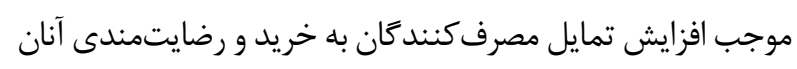
مىشود. همجنين، توليدكنند
موقعيت در بازار بوده است [ع 1]]. براساس اظهارات Stafford و

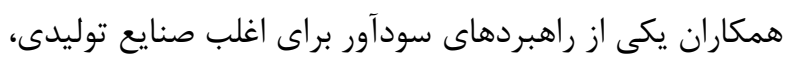

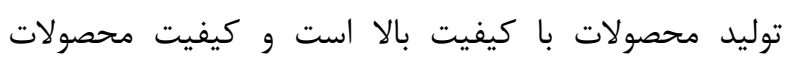

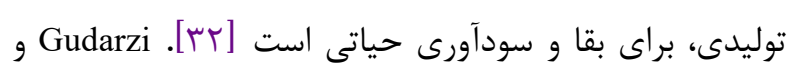
Mohamad Moradi

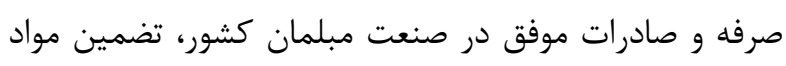

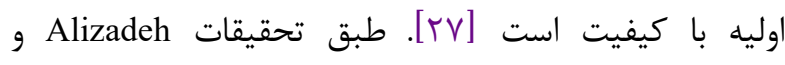

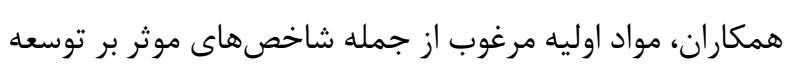

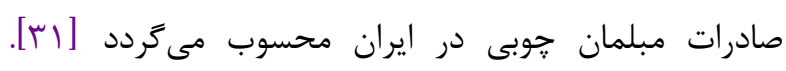

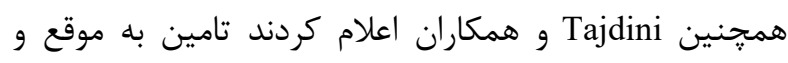

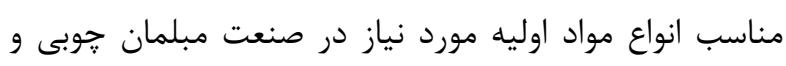

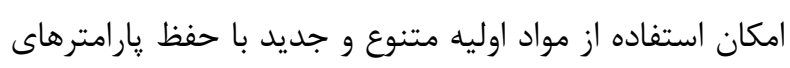
مناسب كيفى، موجب تداوم توليد با كيفيت در واحد محصول

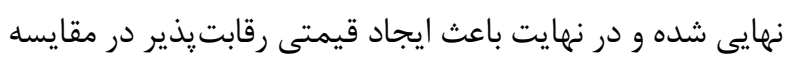

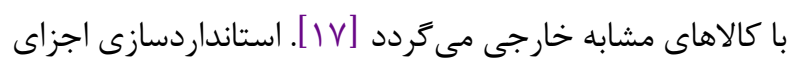

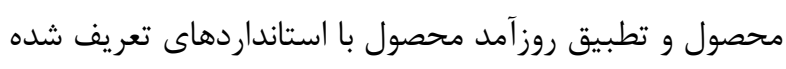

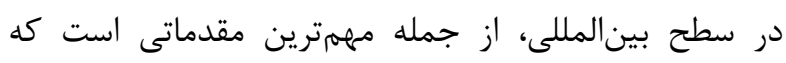

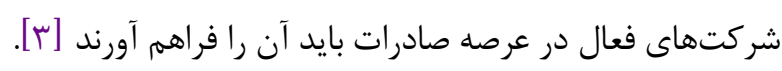

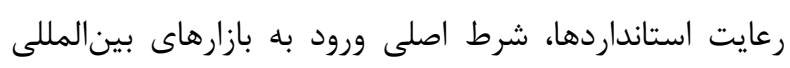

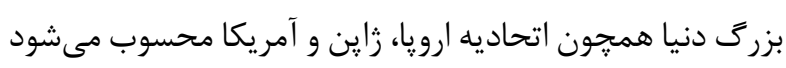

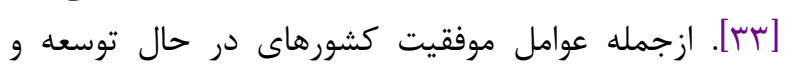

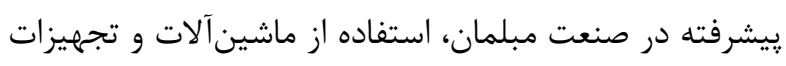
نوين، توليد محصولات باكيفيت و همعام با استانداردهاى

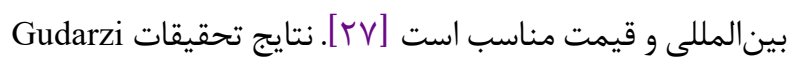
و Tajdini نشان داد، ضعف استانداردهاى داخل در توليد مبلمان

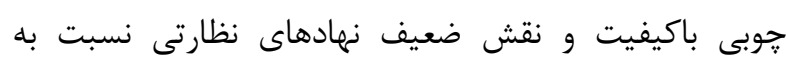

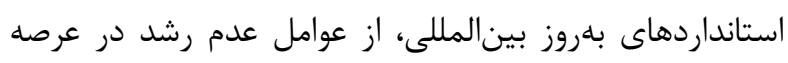

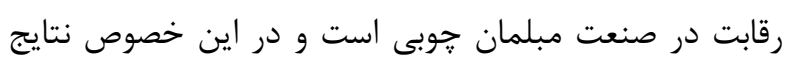

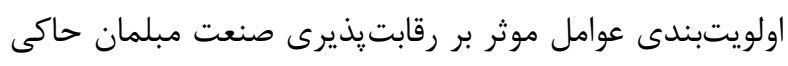

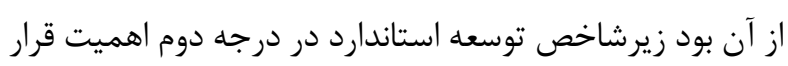

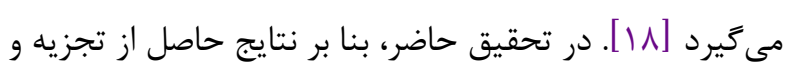

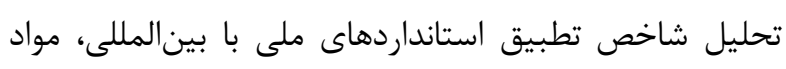

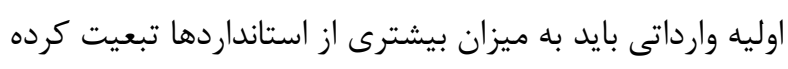

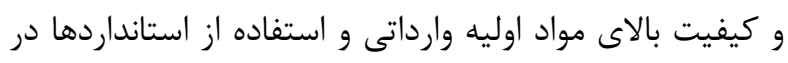

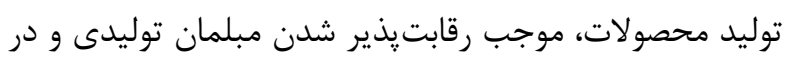

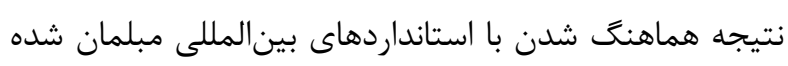

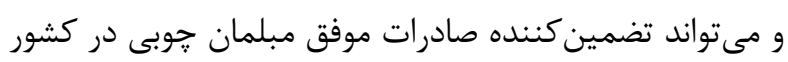




$$
\begin{aligned}
& \text { محققان به سازمان خاصى اعم از دولتى و غيردولتى وابستخى ندارند }
\end{aligned}
$$

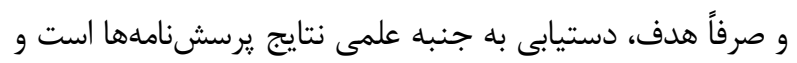

$$
\begin{aligned}
& \text { اطلاعات خصوصى واحدهاى توليدكننده علنى نخواهد شد. } \\
& \text { تقدير و تشكر } \\
& \text { نويسند كان از همهٔ عزيزانى كه در اين تحقيقآنان را يارى } \\
& \text { كردند، سياسگزارى مى كنند. }
\end{aligned}
$$

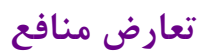

$$
\begin{aligned}
& \text { بين نويسندگان هيجزَنه تعارضى در منافع وجود ندارد. } \\
& \text { منابع مالى } \\
& \text { هزينههاى اين تحقيق توسط نويسندكان تأمين شده است. }
\end{aligned}
$$

\section{References}

1. Azizi M, Mohebbi N, Felice, FD. Evaluation of sustainable development of wooden furniture industry using multi criteria decision making method.Agr Agr Sci Proc. 2016; 8:387-94. [DOI:10.1016/i.aaspro.2016.02.034]

2. Tajdini A, Taghadosi A, Pourmousa Sh, Jahan Latibari, A, Safdari, V Roohnia, M.Study of the effective indices on wooden furniture imports in Iran.Iran JWood Paper Sci Res. 2013; 28(2):205-23.

3. Mesdag MV.Culture-sensitive adaption or global standardization-the duration-of-usage hypothesis.Int Mark Review. 2000; 17(1):74-84

[DOI:10.1108/02651330010314722]

4. Arian A. Effect of :union:s on Iran Furniture Industry Guidance. Paper presented at The First ScientificFunctional Seminar "Development of Iran Furniture and Decoration Industry".Tehran: Senobar. 2007; 1520.

5. Castellucci I, Arezes P, Molenbroek J. Applied anthropometrics in school furniture design: which criteria should be used for standardization? Proceedings of the 5th international conference on applied human factors and ergonomics AHFE. 19-23, July; Kraków, Poland; 2014.

6. Perumal V, Rahman KAA. Analysis of Ergo-Aesthetics Assessment: A case study of public park benches. Proceedings of the 2nd International Colloquium of Art and Design Education Research (i-CADER 2015). Editors: Abidin S.Z, Legino R, Noor H.M, Vermol V.V, Anwar, R, Kamaruzaman M.F; Springer; 2015. [DOI:10.1007/978-981-10-0237-3 46]

7. Jfm M, Ymt KR, Cj S. Revision of the design of a standard for the dimensions of school furniture.

$$
\begin{aligned}
& \text { استانداردها و اصول اركَنوميك داشتهاند و استانداردهاى ملى، } \\
& \text { تطابق زيادى با استانداردهاى بينالمللى داشته است. بنابراين، به } \\
& \text { نظر مىرسد كيفيت مواد اوليه وارداتى و استفاده از استانداردها، } \\
& \text { موجب رقابت يذير شدن مبلمان و هماهنگ شدن با استانداردهاى } \\
& \text { بينالمللى شده و مىتواند تضمين كننده صادرات موفت مبلمان } \\
& \text { دركشور گردد. }
\end{aligned}
$$$$
\text { محدوديت هاى تحقيق }
$$$$
\text { ازجمله محدوديتهاى انجام اين تحقيق مىتوان به عدم تمايل }
$$$$
\text { برخى از توليدكنندگان به همكارى با محققان براى جمعآورى }
$$$$
\text { اطلاعات، نكرانى توليدكنند }
$$

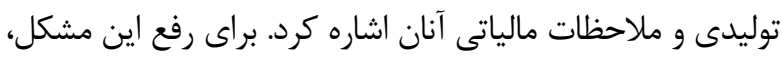$$
\text { محققان به آنان اطمينان دادند كه تحقيق حاضر، شخصى است و ماني }
$$

Ergonomics. $2003 \quad$ May 1;46(7):681-94. [DOI:10.1080/0014013031000085635] [PMID]

8. Gopura RARC. Amarasena KGAH.Design of an ergonomically efficient chair. Paper presented at the 14th ERU Symposium, faculty of engineering. Moratuwa, Sri Lanka; 2008.

9. Taheri S. Ergometer and assessment methods. Tehran: Arvin Press; 1997.

10. Marschall M, Harrington A, Steele J. Effect of workstation design on sitting posture in young children. Erg. 1995; 38(9):1932-40. [DOI:10.1080/00140139508925241] [PMID]

11. Gofrani M, Noori H. Design and manufacture of domestic sofas with ergonomic indices. J Ergo. 2016; 4(1):64-71. [DOI:10.21859/joe-04018]

12. Motamedzade M, Hassan Beigi MR, Choobineh AR, Mahjoob H.Design and development of an ergonomic chair for Iranian office workers. J Adv Med Biomed Res.2009; 17(68):45-52.

13. Ghofrani M, Motamedzade M, Aghaie MR, Mohammad Moradi Z. Designing and manufacturing of ergonomic training furniture for mapping based on the physical dimensions of boy students (Case study of Mashhad Art Schools). Iran J Ergon. 2019; 7(3):11-23.

14. Fathollahzadeh A. Standardization, a way to increase the quality of the wooden furniture manufacturing industry. Paper presented at the 2nd international conference on the world trade furniture, interior design;20 June 2009; Tabriz, Iran; 2009.

15. Rangavar H. Khojasteh khosro S. Investigating the effective index on customer's choice in buying furniture. Iran J Wood Paper Ind. 2014; 1(5): 153-64. 
16. Mohamad Moradi Z, Ghofrani M. Investigating the effectiveness and impact of factors affecting the growth and economic development of the classical furniture industry (Case study: Tehran province).Iran J Wood Paper Ind.2020; 11(2):281-92.

17. Tajdini A, Rabie D, Jahan Latibari A, Pourmousa, SH. Study on effective indices on exports of wooden furniture in Iran. J Sci Tech Natur Resource. 2011; 6:71-87.

18. Gudarzi E, Tajdini A. Applying analytical hierarchy process in ranking of the effective indices on competitiveness of the wooden furniture industry in Iran. Iran J Wood Paper Sci Res.2015; 30(4):578-94.

19. Ghofrani M, Ghiyasvand A. Investigation of the domestic living furniture producer's point of view on the manufacturing and selling of these products. Iran J Wood Paper Sci Res. 2016; 31(4):581-94.

20. Ghofrani M, Zare A, Aziz M. Identifying and prioritizing indicators and effective solutions to optimize the wood consumption in construction of classical furniture by using AHP (case study: Qom province).IranJWood Paper Ind. 2017; 7(4):573-89.

21. Kolter P. Armstrong G. Principles of marketing. New York: Pearson; 2008. P. 856.

22. Najafiyan $M$, Aghababaei $H$. The quantity and quality investigation of the manufacture of furniture and its effect on economics.Paper presented at the First National Conference on Wood and Lignocellulosic Products; 7 May 2015; Gonbad-e Kavoos; Iran. 2015.

23. Mohebbi N.A, Azizi M, Ziaie M, Hosseinzadeh O. Providing a model for sustainable development of Iran wooden furniture industry. J Wood Forest Sci Tech. 2017; 24(1):117-30.

24. Kotler P, Keller KL, Brady M, Goodman M, Hansen T. Marketing Management. New York: Pearson. 2009.

25. Gholamiyan H, Taghiyari HR. Standardization of wooden furniture design, with ergonomic body. Paper presented at The Second International Conference on the World Trade Furniture, Interior Design and Decoration (Deco 2009). 27-28, September, Tehran, Iran; 2009.
26. Caroline K. The Beauty of Fit: Proportion and anthropometry in chair design. In partial fulfillment of the requirements for the degree of masters of industrial design in the college of architecture. Georgia: Georgia Institute of Technology; 2005.

27. Ghofrani M, Mohamad Moradi, Z. Identification and prioritization of factors affecting competitiveness of classic furniture using ANP (case study: Tehran province).IranJWood Paper Sci Res. 2017; 33(2):17995.

28. Taghadosi AH. Study on indices influencing the furniture importation in Iran. MA thesis. Karaj: Islamic Azad University of Karaj.2011; 110.

29. Ghofrani M, Rahimi F. The impress and employment. Paper presented at the 1 st conference on Development of the Furniture Industry of Iran for presence in the global markets.24 April 2008; Tehran, Iran. 2008.

30. Reitenbach EFR, Jochems AJ, Molenbroek FM, Ball R, Van Eijk DJ. User experience of office chairs and anthropometrics of female Chinese and Hong Kong Chinese office and factory workers. Ergon Open J. 2009; 2:1-12. [DOI:10.2174/1875934300902010001]

31. Alizadeh H, Faezipoor M, Azizi M, Ziaie M. Determine the parameters affecting the development of Iran's exports of wooden furniture using Analytic Hierarchy Process (AHP). J Forest Wood Prod. 2014; 66(4):477791

32. StaffordMR, Stafford TF, Wells BP. Determinants of service quality and satisfaction in the auto casualty claim process. J Service Mark. 2009; 12(6):426-40. [DOI:10.1108/08876049810242687]

33. Ziaie M. Global furniture market at a glance: Major players, strategic trends, challenges and opportunities. J Wood Paper Ind.2010; 48(6):48-54.

34. Maleki Gholandoz M, Tajdini, A, Pourmosa, Sh, Agharafiei E. Identifying and ranking of factors affecting customer satisfaction of the household wood furniture industry by Multi Attribute Decision making method (Case Study: home furniture). Iran J Wood Paper Sci Res. 2014; 4(28):691-708. 